
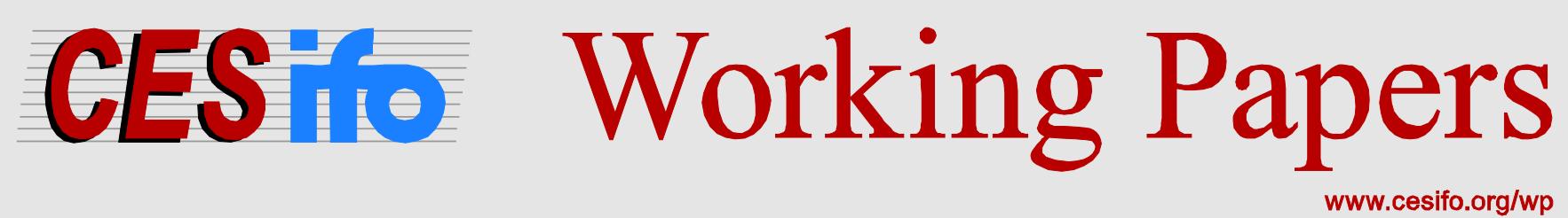

\title{
Second-Best Income Taxation with Endogenous Human Capital and Borrowing Constraints
}

\author{
Bas Jacobs \\ Hongyan Yang
}

CESIFO WORKING PAPER NO. 4155

CATEGORY 1: PUBLIC FinANCE

MARCH 2013

An electronic version of the paper may be downloaded

- from the SSRN website:

- from the RePEc website:

- from the CESifo website:

WWW.SSRN.com

www.RePEc.org

www.CESifo-group.org/wp

\section{CESifo}




\title{
Second-Best Income Taxation with Endogenous Human Capital and Borrowing Constraints
}

\begin{abstract}
We formulate a two-period life-cycle model of saving, labor supply, and human capital investments when individuals differ in ability and initial wealth. Borrowing constraints prevent individuals to optimally smooth consumption over the life-cycle and to optimally invest in human capital. We show that the optimal linear income tax is positive - even in the absence of any redistributional concerns. A progressive income tax is efficient because it relaxes borrowing constraints by redistributing resources from the unconstrained to the borrowing constrained stages of the life-cycle. Hence, consumption is smoothed better and investments in human capital increase. The progressive income tax is a second-best instrument to correct the non-tax distortion in the capital market. The equity-efficiency tradeoff is therefore less severe when progressive income taxes mitigate capital market imperfections. Simulations demonstrate that optimal income taxes are substantially higher when they alleviate credit constraints.
\end{abstract}

JEL-Code: H210, I200, J200.

Keywords: labor taxation, human capital investment, credit constraints.

Bas Jacobs

Erasmus School of Economics

Erasmus University Rotterdam

Rotterdam / The Netherlands

bjacobs@ese.eur.nl
Hongyan Yang

Jacobs University Bremen \&

University of Bremen

Bremen / Germany

h.yang@uni-bremen.de

The authors thank Dan Anderberg, Dirk Schindler, Bernd Genser, Mathias Kifmann and seminar participants at the University of Konstanz, the International Public Finance Conference in Cape Town, the Association for Public Economic Theory Conference in Galway and the European Economic Association Conference in Barcelona for useful comments and suggestions. All remaining errors are our own. Bas Jacobs gratefully acknowledges financial support from the Dutch Organisation for Sciences (NWO Vidi Grant No. 452-07-013, 'Skill Formation in Distorted Labor Markets'). 


\section{Introduction}

This paper examines optimal income taxation and human capital formation in an economy where individuals are subject to binding credit constraints. Empirical evidence for credit constraints is presented in two strands of the literature. First, (poor) individuals can experience difficulties financing their higher education as shown in Kane (1996), Keane and Wolpin (2001), Plug and Vijverberg (2005), Belley and Lochner (2007), Stinebrickner and Stinebrickner (2008) and Lochner and Monge-Naranjo (2011) 1 1 Second, ample empirical evidence for binding borrowing constraints is found when empirically testing the life-cycle hypothesis in consumption. See Attanasio and Weber (2010) for an excellent overview of this literature. Binding credit constraints preventing individuals to invest optimally in human capital could contribute to persistence in income mobility, result in larger inequality, strengthen segregation of neighborhoods, and decrease economic growth (Loury, 1981; Galor and Zeira, 1993; Durlauf, 1996, and Benabou, 1996a,b; De Gregorio, 1996; Mookherjee and Ray, 2003; Galor and Moav, 2004).

The purpose of this paper is to analyze optimal redistributive tax policies when individuals cannot borrow the funds to smooth consumption and to finance human capital investments. To that end, we develop a two-period life-cycle model, where individuals make educational investments in first period and they work in the second period. Exogenous constraints restrict the amount of borrowing that can be made by individuals in the first period of their life cycle, since poor individuals (or their parents) cannot collateralize human capital to finance investments in education (of their children). In a non-slave state legal restrictions prevent individuals engaging in a contract that employs future income as collateral. However, the government can circumvent this constraint as it has a claim on all acquired human capital through the tax system (see also Stiglitz, 1994; Jacobs and van Wijnbergen, 2007). The government thus sets linear income taxes so as to maximize social welfare. Due to informational problems in verifying ability and initial wealth, individualized lump-sum taxes are ruled out. Therefore, the government cannot perfectly eliminate all credit constraints or redistribute income without causing distortions in labor supply and human capital investment.

We demonstrate that the optimal income tax is progressive even in representativeagent settings where distributional concerns are absent. That is, we provide a case for distortionary taxation on grounds of efficiency only. The intuition is that, as long as incomes are increasing over the life-cycle, progressive tax systems redistribute resources from later stages to earlier stages in the life-cycle. By taxing later incomes at higher average rates than current incomes, while redistributing the revenue through lump-sum

\footnotetext{
${ }^{1}$ Consistent with the presence of credit constraints Kane (1995) and van der Klaauw (2002) identify large impacts of financial aid on college enrollment. Acemoglu and Pischke (2001) show that family income plays an important role in determining educational attainment. Caneiro and Heckman (2002) point out that credit constraints are relevant for about $8 \%$ of the youth in the US.
} 
transfers, the progressive income tax alleviates credit constraints. Hence, not only consumption is smoothed better, but also investments in human capital increase. The labor tax trades off the welfare gains of alleviating credit constraints against the tax distortions in labor supply and human capital formation. The extent to which individuals are credit constrained, and the tax elasticities of labor supply and educational investment determine the optimal tax rate.

In an extension of the model with heterogenous individuals, we show that the results derived under homogenous individuals carry over to the more general case with heterogeneous individuals. We show that with credit constraints the trade-off between equity and efficiency is less severe, since redistribution generates not only equity gains, but also efficiency gains. Hence, when distributional concerns are allowed for, the case for progressive income taxation is strengthened further.

We simulate optimal taxes using an empirically plausible calibration of our model. Our simulations demonstrate that optimal taxes are about 50 percent higher when credit constraints are present compared to the optimal tax rates when credit constraints are absent. Moreover, the optimal tax rate in the absence of any redistributional concerns, i.e. the efficient optimal tax rate, would be around 25 percent. Our simulation results are very robust to alternative specifications of the model.

Our paper relates in a number of ways to the existing literature. First, this paper analyzes credit constraints in optimal-tax models with human capital investments. Almost the entire literature on human capital and optimal taxation assumes perfect capital markets or static human capital models in which capital markets play no substantive role, see, for example, Ulph (1977), Hare and Ulph (1979), Tuomala (1990), Eaton and Rosen (1980), Hamilton (1987), Nielsen and Sørensen (1997), Jones, Manuelli and Rossi (1997), Judd (1999), Anderberg and Andersson (2003), Anderberg (2009), Jacobs (2005, 2012), Bovenberg and Jacobs (2005), Maldonado (2008), Jacobs and Bovenberg (2010, 2011), Schindler (2011) or Jacobs et al. (2012).

Second, the paper being conceptually closest to ours is Hubbard and Judd (1986). They simulate a life-cycle model to demonstrate that progressive income taxation compared to proportional income taxation is welfare improving when credit constraints are binding. The intuition is the same as ours: the progressive income tax redistributes resources over the life-cycle and allows for better consumption smoothing. Our paper, however, provides a formal proof for their finding as a special case of our model in which educational investment is kept exogenous. Hoff and Lyon (1995) also show that redistributive income taxation improves welfare by mitigating adverse selection in the capital market. Taxing labor income progressively and rebating the tax revenue through lumpsum transfers increases collateralizable wealth. Progressive taxes thereby moderate inefficient overinvestment in education. Our model in contrast emphasizes underinvestment in human capital resulting from binding credit constraints. 
Third, earlier work by Loury (1981), Glomm and Ravikumar (1992), Benabou (1996a, 1996b), and Fernandez and Rogerson $(1996,1998)$ demonstrates that when credit constraints are binding public provision of education or equalizing expenditure on education among communities can increase income equality, reduce segregation, promote income mobility, and boost economic growth. Tobin (1980) also points out that government policy should help credit constrained individual to move resources from the future to the present. However, this literature has not yet conducted an analysis of optimal redistributive policies when individuals face binding credit constraints.

Fourth, our paper also contributes to an extensive literature, which emphasizes the potentially efficiency-enhancing effects of distortionary taxes in second-best settings. See also Van der Ploeg (2006a) for an overview. We show that the introduction of a distortionary tax instrument, can reduce a pre-existing non-tax distortion in the economy, i.e., the credit constraint. For example, Akerlof (1976) shows that the introduction of a distortionary income tax helps to tame the 'rat race' and reduces the individuals' excessive incentives to work. Related is Layard $(1980,2005)$ who argues that progressive taxation is welfare-improving because individuals are involved in status races ('keeping up with the Joneses') and exhibit habit persistence, both giving excessive incentives to work. Labormarket imperfections arising from trade unions, efficiency wages and search frictions also provide second-best arguments for progressive taxes (see Koskela and Vilmunen, 1996; Pissarides, 1998; Sørensen, 1999; Boone and Bovenberg, 2002; Van der Ploeg, 2006b; and Bovenberg 2006). Unions set wages above market clearing levels when unemployment benefits improve the outside options of workers. Also firms pay too high efficiency wages in order to recruit, to retain and to motivate workers when workers face attractive outside options. Progressive taxes punish both unions and firms to bid up wages, so that wages are moderated, and unemployment decreases $2^{2}$ Progressive taxation could also correct search frictions in labor market. Progressive taxation lowers the wage demands by workers, which increases vacancies and expands employment. This is optimal if workers have too much bargaining power compared to firms, i.e., when the Hosios (1990) condition is not met. In the presence of missing insurance markets, progressive taxation redistributes income across different states of natures and improves upon efficiency by partially replacing the missing insurance market (Eaton and Rosen, 1980; Varian, 1980; Jacobs et al., 2012).

The remainder of this paper is organized as follows. Section 2 presents our life-cycle model with imperfect credit markets and human capital investment. Optimal tax policies are analyzed in section 3 in an economy with a representative individual, which focuses on optimal efficient taxation to relax borrowing constraints. In section 4 we extend the

\footnotetext{
${ }^{2}$ Van Ewijk and Tang (2007) show that education subsidies are optimal in order to off-set the disincentives on human capital investments when the government uses progressive taxes to lower union's wage demands.
} 
model to a setting with heterogeneous individuals and show how income redistribution produces equity gains and alleviates credit constraints. The last section concludes.

\section{Model}

The economy is populated by a continuum of individuals living for two periods. The mass of all individuals is normalized to one. Individuals differ in their ability $n$ and initial wealth $\omega$. Ability and wealth have a cumulative joint distribution $F(n, \omega)$, which has supports $[\underline{n}, \infty)$ and $[\underline{\omega}, \infty)$. We use a subscript to denote the type of individual by its ability and initial wealth, while a superscript is used to label the period in the life-cycle.

We consider a two-period life-cycle model of educational investment, labor supply, saving and borrowing constraints. In the first period the individual does not work, but invests in education and consumes. In the second period, the individual supplies labor and consumes all its wealth.

The resource costs of human capital investment $e_{n \omega}$ are assumed to be non-verifiable, and therefore non-subsidizable. Part of the time and study effort invested in education is non-verifiable. It can also be difficult for the government to distinguish direct costs of education (books, computers, etc) from pure consumption ${ }^{3}$ We normalize the unit cost of education and consumption goods to one. We assume that costs of education are not tax deductible. However, one can argue that the main cost of education - forgone earnings - is in fact tax deductible. We demonstrate later that our main results would only be strengthened if we would assume that all costs of education would be fully deductible.

Besides educational investment, the individual decides on its consumption in first period $c_{n \omega}^{1}$ and saving $a_{n \omega}$. Consequently, the first-period budget constraint is

$$
a_{n \omega}=-e_{n \omega}+\omega+g-c_{n \omega}^{1}
$$

where $g$ is the time-invariant lump-sum transfer.

Individuals are only allowed to borrow a maximum of $a_{o}$ at the capital market, implying the following borrowing constraint:

$$
a_{n \omega}+a_{o} \geq 0 .
$$

This assumption reflects the fact that individuals have limited access to loans to finance consumption and educational investments. The (exogenous) interest rate equals $r$ and is the same for saving and borrowing.

\footnotetext{
${ }^{3}$ The extension to allow for education subsidies, besides taxation, is left for future research. A part of educational costs is verifiable, e.g. institutional and some direct costs of education. But, as long as some investments are non-verifiable, education subsidies cannot off-set all distortions from taxes or capitalmarket imperfections on human capital, and our results for optimal income taxes remain qualitatively valid.
} 
Second-period labor supply is denoted by $l_{n \omega}$. Gross labor income $z_{n \omega}$ depends on educational investment $e_{n \omega}$, labor supply $l_{n \omega}$ and ability $n$ :

$$
z_{n \omega} \equiv n l_{n \omega} \phi\left(e_{n \omega}\right), \quad \phi^{\prime}(\cdot)>0, \quad \phi^{\prime \prime}(\cdot)<0
$$

where $\phi\left(e_{n \omega}\right)$ is the production function for human capital with positive but diminishing marginal returns to human capital investment.

Second-period consumption equals after-tax labor income, saving plus interest income and the lump-sum transfer:

$$
c_{n \omega}^{2}=(1-t) n l_{n \omega} \phi\left(e_{n \omega}\right)+(1+r) a_{n \omega}+g,
$$

where $t$ denotes the labor tax rate. We rule out taxes on saving, since we will focus mainly on credit-constrained individuals. Taxes on saving would not yield any revenues when savings are zero. $4^{4}$

The individual characteristics $(n$ and $\omega)$ and individual decisions $\left(e_{n \omega}, a_{n \omega}\right.$ and $\left.l_{n \omega}\right)$ are assumed to be private information. In line with Mirrlees (1971) only total labor income is verifiable to the government. Consequently, government has to rely on distortionary labor taxes to redistribute income. With a flat tax rate and positive non-individualized lump-sum transfers the income tax is progressive. Age-specific lump-sum transfers would be available if the transfers could be conditioned on age. However, we rule out agespecific transfers, since most legal systems do not allow for age-discrimination. Therefore, the transfers are identical in both periods. The non-verifiability of $\omega$ implies that the government can neither levy taxes on initial wealth nor condition transfers upon initial wealth of each individual. The informational requirement for levying a flat tax is that the government only needs to verify aggregate labor income.

Individuals derive utility from consumption in both periods and disutility from labor. The utility function is assumed to be separable in consumption and labor:

$$
U_{n \omega} \equiv u\left(c_{n \omega}^{1}, c_{n \omega}^{2}\right)-v\left(l_{n \omega}\right), \quad u_{1}, u_{2}, v^{\prime}>0, \quad u_{11}, u_{22},-v^{\prime \prime}<0, \quad u_{12} \geq 0
$$

The subutility function $u$ is concave in both arguments. The subscripts refer to the derivatives with respect to the first and the second argument of the utility function, respectively. The disutility of labor $v(\cdot)$ is increasing and convex in $l_{n \omega}$. The individual chooses educational investment $e_{n \omega}$, saving $a_{n \omega}$ and labor supply $l_{n \omega}$ to maximize utility (5) subject to the budget constraints (1), (4), and the credit constraint (2).

\footnotetext{
${ }^{4}$ Hubbard and Judd (1986) and Aiyagari (1995) show that capital taxation is welfare-improving with binding credit constraints because capital taxation results in redistribution from non-credit constrained individuals (who do save) to credit constrained individuals (who do not save). Consequently, credit constraints are alleviated, but this comes at a price of distorting the saving decisions of the non-constrained individuals.
} 
After substituting budget constraints for $c_{n \omega}^{1}$ and $c_{n \omega}^{2}$ we can formulate the following Lagrangian $\mathcal{L}$ for the individual's maximization problem

$$
\begin{aligned}
\max _{\left\{a_{n \omega}, e_{n \omega}, l_{n \omega}\right\}} \mathcal{L}_{n \omega} & \equiv u\left(-e_{n \omega}+\omega+g-a_{n \omega} ;(1-t) n l_{n \omega} \phi\left(e_{n \omega}\right)+(1+r) a_{n \omega}+g\right) \\
& -v\left(l_{n \omega}\right)+\varphi_{n \omega}\left(a_{n \omega}+a_{o}\right)
\end{aligned}
$$

where $\varphi_{n \omega}$ is the Kuhn-Tucker multiplier on the credit constraint (2). The multiplier $\varphi_{n \omega}$ is the shadow price for borrowing more than the borrowing limit, i.e., it measures the marginal increase in individual utility if the individuals' borrowing limit $a_{o}$ increases with one unit. We should note that the shadow price $\varphi_{n \omega}$ is different for individuals with different $n$ and $\omega$. The first-order conditions for utility maximization are given by

$$
\begin{aligned}
\frac{\partial \mathcal{L}_{n \omega}}{\partial a_{n \omega}} & =-u_{1}\left(c_{n \omega}^{1}, c_{n \omega}^{2}\right)+(1+r) u_{2}\left(c_{n \omega}^{1}, c_{n \omega}^{2}\right)+\varphi_{n \omega}=0, \\
\varphi_{n \omega} & \geq 0, \quad \varphi_{n \omega}=0 \quad \text { if } \quad a_{n \omega}+a_{o}>0, \\
\frac{\partial \mathcal{L}_{n \omega}}{\partial e_{n \omega}} & =-u_{1}\left(c_{n \omega}^{1}, c_{n \omega}^{2}\right)+u_{2}\left(c_{n \omega}^{1}, c_{n \omega}^{2}\right)(1-t) n l_{n \omega} \phi^{\prime}\left(e_{n \omega}\right)=0, \\
\frac{\partial \mathcal{L}_{n \omega}}{\partial l_{n \omega}} & =u_{2}\left(c_{n \omega}^{1}, c_{n \omega}^{2}\right)(1-t) n \phi\left(e_{n \omega}\right)-v^{\prime}\left(l_{n \omega}\right)=0 .
\end{aligned}
$$

If individuals are not credit constrained $\left(\varphi_{n \omega}=0\right)$, the consumption and educational choices of the household can be summarized as

$$
\frac{u_{1}\left(c_{n \omega}^{1}, c_{n \omega}^{2}\right)}{u_{2}\left(c_{n \omega}^{1}, c_{n \omega}^{2}\right)}=(1-t) n l_{n \omega} \phi^{\prime}\left(e_{n \omega}\right)=1+r .
$$

Intertemporal consumption choices are not distorted since the marginal rate of intertemporal substitution in consumption equals one plus the interest rate, which is the marginal rate of intertemporal transformation. The optimality condition for investment in education equates the marginal costs of investing one unit of resources in education $(1+r)$ with the marginal benefits of one unit of resources invested in education $\left((1-t) n l_{n \omega} \phi^{\prime}\left(e_{n \omega}\right)\right)$. Note that the marginal benefits of education increase if individuals supply more labor. Hence, labor and education are complements in generating gross income. As long as the marginal income tax rate is positive, the tax system distorts educational investments, since the marginal benefits are taxed, whereas the marginal costs are not.

For credit constrained individuals $\left(\varphi_{n \omega}>0\right)$ we have $a_{n \omega}=-a_{o}$, and we obtain

$$
\frac{u_{1}\left(c_{n \omega}^{1}, c_{n \omega}^{2}\right)}{u_{2}\left(c_{n \omega}^{1}, c_{n \omega}^{2}\right)}=(1-t) n l_{n \omega} \phi^{\prime}\left(e_{n \omega}\right)>1+r .
$$

The credit constraint creates a wedge in intertemporal consumption choices, i.e., a difference between marginal rate of intertemporal transformation $(1+r)$ and marginal rate of 
intertemporal substitution $\left(\frac{u_{1}(\cdot)}{u_{2}(\cdot)}\right)$, implying that individuals would like to transfer more consumption from the second to the first period if they could. Thus, a binding credit constraint renders income in the first period relatively more valuable to the individual than in the second period. Investment in education of credit-constrained individuals is distorted by the borrowing constraint, since the marginal returns to investment in human capital $\left((1-t) n l_{n \omega} \phi^{\prime}\left(e_{n \omega}\right)\right)$ are larger than the marginal returns to financial saving $(1+r)$.

We can define the implicit tax $\pi_{n \omega}$ on human capital investment arising from the credit constraint as:

$$
\pi_{n \omega} \equiv 1-(1+r) \frac{u_{2}(\cdot)}{u_{1}(\cdot)} .
$$

$\pi_{n \omega}$ measures to which extent the intertemporal consumption choices are distorted. An intertemporal consumption wedge implies that $\pi_{n \omega}>0$, and $\frac{u_{1}(\cdot)}{u_{2}(\cdot)}>1+r$. If the credit constraint is slack, there is no distortion caused by imperfect capital markets: $\pi_{n \omega}=0$, and the standard Euler-equation applies.

Using the definition of $\pi_{n \omega}$, the first-order condition for educational investment can be rewritten as

$$
\left(1-\pi_{n \omega}\right)(1-t) n l_{n \omega} \phi^{\prime}\left(e_{n \omega}\right)=1+r .
$$

From this equation we can see that human capital investment is reduced, because the binding credit constraint acts as an additional, implicit tax on the return from human capital investment. Nevertheless, the value of $\pi_{n \omega}$ is different for individuals differing in both $n$ and $\omega$. In particular, it decreases with initial wealth until it becomes zero when individuals are not credit constrained. It increases with ability $n$ - for given levels of initial wealth $\omega-$, because more able individuals have a higher marginal return to education $\left(n l_{n \omega} \phi^{\prime}(\cdot)\right)$ and, consequently, would like to borrow more in order to finance larger investment in education.

First-order conditions are necessary, but not sufficient due to the positive feedback between learning and labor supply. If we assume that the sub-utility function $u$ is homogeneous of degree one, we derive that the second-order condition requires $\alpha_{n \omega}+\beta_{n \omega} \varepsilon_{n \omega}<0$, where $\beta_{n \omega} \equiv \frac{\phi^{\prime}\left(e_{n \omega}\right) e_{n \omega}}{\phi\left(e_{n \omega}\right)}, \alpha_{n \omega} \equiv \frac{\phi^{\prime \prime}\left(e_{n \omega}\right) e_{n \omega}}{\phi^{\prime}\left(e_{n \omega}\right)}$ and $\varepsilon_{n \omega} \equiv\left(\frac{v^{\prime \prime}\left(l_{n \omega}\right) l_{n \omega}}{v^{\prime}\left(l_{n \omega}\right)}\right)^{-1}$ denote the elasticity of the human capital production function, the elasticity of the marginal return in human capital production function, and the elasticity of labor supply, respectively. (See Appendix A.1.) A sufficiently low elasticity of labor supply $\varepsilon_{n \omega}$, a sufficiently low elasticity of the human capital production function $\beta_{n \omega}$, and a sufficiently high elasticity of the marginal return to human capital investment (in absolute value) ensure that the feedback between labor supply and education dampens out and interior solutions are obtained. We assume in the remainder that the second-order conditions are always respected.

The first-order conditions and the household budget constraints jointly determine optimal investment in education, labor supply, and consumption choices as functions of the policy parameters $g$ and $t$, ability $n$ and initial wealth $\omega$. By indicating the optimized 
values with an asterisk, we can write the indirect utility function as

$$
V_{n \omega}(g, t) \equiv u\left(c_{n \omega}^{1 *}, c_{n \omega}^{2 *}\right)-v\left(l_{n \omega}^{*}\right)
$$

Applying Roy's lemma yields the following derivatives with respect to the policy instruments: $\frac{\partial V_{n \omega}}{\partial g}=u_{1}(\cdot)+u_{2}(\cdot)$, and $\frac{\partial V_{n \omega}}{\partial t}=-u_{2}(\cdot) n l_{n \omega} \phi\left(e_{n \omega}\right)$.

For later reference, we also derive the Slutsky-equations for education and labor supply (see Appendix A.2). With capital market failures, deriving the compensated demand and supply functions is not trivial, because the exact timing of the compensation to keep utility fixed matters. If the credit constraint is slack, one unit of compensation given in first period is the same as the discounted value of one unit of compensation given in second period. However, if the credit constraint is binding, the value of one unit of compensation given in first period is higher than the discounted value of one unit of compensation in the second-period. We derive the Slutsky-equations where a uniform income compensation is given in both periods, e.g. by a higher lump-sum transfer:

$$
\begin{aligned}
\frac{\partial e_{n \omega}}{\partial t} & =\frac{\partial e_{n \omega}^{c}}{\partial t}-\frac{u_{2}(\cdot)}{u_{1}(\cdot)+u_{2}(\cdot)} n l_{n \omega} \phi\left(e_{n \omega}\right) \frac{\partial e_{n \omega}}{\partial g}, \\
\frac{\partial l_{n \omega}}{\partial t} & =\frac{\partial l_{n \omega}^{c}}{\partial t}-\frac{u_{2}(\cdot)}{u_{1}(\cdot)+u_{2}(\cdot)} n l_{n \omega} \phi\left(e_{n \omega}\right) \frac{\partial l_{n \omega}}{\partial g}
\end{aligned}
$$

where $e_{n \omega}^{c}$ denotes the compensated demand for education, and $l_{n \omega}^{c}$ denotes the compensated supply of labor.

\section{Optimal taxation without redistribution}

This and the next sections derive optimal tax policies with and without redistributional concerns. We assume that the government is benevolent and has full commitment. That is, the government announces the tax schedule before individuals make their decisions and fully commits to it: $5^{5}$ In this section we discuss optimal taxation when individuals are all identical and there are, consequently, no redistributional concerns. We therefore suppress the subscripts $n$ and $\omega$. Moreover, we assume that the initial wealth of the representative individual is not sufficient to finance the optimal level of human capital investment. Consequently, the credit constraint is binding and educational investment is inefficiently low. The case with a slack credit constraint is very straightforward. In particular, first-best would then be obtained, since all individual choices would be efficient and the government would have access to lump-sum taxes.

We focus on optimal tax policy when age-specific lump-sum transfers are not available

\footnotetext{
${ }^{5}$ However, in view of the sunk character of the educational investment, the optimal policy is generally not time-consistent. Therefore, a benevolent government may want to renege on its announcements and re-optimize taxes after investments have been made, see also Pereira (2009).
} 
to the government. If age-specific lump-sum transfers would be available in a setting with a representative individual, it would follow trivially that the credit constraint could be perfectly removed without any efficiency costs. In particular, a policy with age-specific transfers can be viewed as a government loan where the government provides an amount of lump-sum income to each young individual and requires them to pay it back, including interest costs, with a lump-sum tax when they are old. Consequently, government can act perfectly as a lender to replace the missing capital market without resorting to distortionary taxes on labor income. In heterogeneous individual settings, which we will analyze in the next section, a first-best optimum would require both age-specific and individualized lump-sum transfers, which are not feasible due to the informational constraints we have imposed on $n$ and $\omega$.

The tax system thus consists of a flat tax on labor income and uniform lump-sum transfers in both periods. Without loss of generality we assume that there are no exogenous government expenditures ${ }^{6}$ Tax revenue from labor taxation is used only to finance lump-sum transfers $g$ in both periods. The government budget constraint is therefore given by:

$$
\operatorname{tnl} \phi(e)=(2+r) g
$$

The tax payment in the second period should be equal to the value of transfers provided in both periods plus interest. Note that we express the government budget constraint in terms of second-period income. We assume that government is not credit constrained, as opposed to individual households. Intuitively, private markets will make government borrowing available, since the government can effectively collateralize human capital through the tax system. By the government's ability to tax income, the government can secure claims on the future returns from human capital (Jacobs and Van Wijnbergen, 2007). However, alleviating the credit constraint through transfers is costly because labor supply is distorted, and the first-best allocation cannot be obtained.

The government chooses $g$ and $t$ in order to maximize indirect utility of the representative individual. The Lagrangian $\mathcal{W}$ for maximizing social welfare is given by

$$
\max _{\{g, t\}} \mathcal{W} \equiv V(g, t)+\eta(\operatorname{tnl} \phi(e)-(2+r) g)
$$

where $\eta$ is the shadow value of public resources. The optimal uniform lump-sum transfer $g$ satisfies (see Appendix A.3):

$$
\frac{u_{1}(\cdot)+u_{2}(\cdot)}{\eta}+\operatorname{tnl} \phi^{\prime}(e) \frac{\partial e}{\partial g}+\operatorname{tn} \phi(e) \frac{\partial l}{\partial g}=2+r
$$

where we used Roy's lemma: $\frac{\partial V}{\partial g}=u_{1}(\cdot)+u_{2}(\cdot)$. Equation 20 states that the marginal

\footnotetext{
${ }^{6} \mathrm{An}$ exogenous revenue requirement would not change our main result that progressive income taxes are optimal.
} 
social benefit of providing one unit of income in both periods (including the indirect income effects on the tax bases) should be equal to the marginal resource cost of providing one unit of income in both periods (see also Atkinson and Stiglitz, 1980).

The first-order condition for optimal income tax rate can be reformulated as (see Appendix A.3):

$$
\frac{t}{1-t}=\frac{\pi(1-\chi)}{\varepsilon_{l t}+\beta \varepsilon_{e t}}
$$

where $\varepsilon_{l t} \equiv-\frac{\partial l^{c}}{\partial t} \frac{1-t}{l}$ and $\varepsilon_{e t} \equiv-\frac{\partial e^{c}}{\partial t} \frac{1-t}{e}$ denote the compensated tax elasticities of labor supply and educational investment, respectively. $\beta \equiv \frac{\phi^{\prime}(e) e}{\phi(e)}$ is the elasticity of human capital production function, and $1-\chi \equiv \frac{1+r}{2+r-\pi}=\left(1+\frac{u_{2}(\cdot)}{u_{1}(\cdot)}\right)^{-1}$. The optimal tax trades off the welfare gains of alleviating the credit constraint (numerator) against the efficiency costs of doing so (denominator). At the optimum, the welfare gains of alleviating the credit constraint should be equalized to its efficiency costs. The more individuals are credit constrained, as measured by a higher value of $\pi$, the larger is the welfare gain of a higher tax rate. The compensated tax elasticities $\varepsilon_{l t}$ and $\beta \varepsilon_{e t}$ measure the tax distortions on labor supply and educational investment. The more elastically labor supply or educational investments respond to the tax rate $t$, the larger are tax distortions, and the lower should be the optimal tax rate.

$\chi \equiv \frac{1-\pi}{2+r-\pi}$ measures the inefficiency of an age-independent tax system compared to a tax system where the transfer is provided in the first period only. In the latter case we would obtain $\chi=0$. Intuitively, for a given tax rate (and, therefore, for a given level of efficiency costs) the resources available to be transferred to the first period are lower when the same amount has to be transferred to the second period as well. Hence, for one unit of revenue raised in second period by the labor tax only $\frac{1+r}{2+r}$ can be transferred to the first period. Due to the 'leak' of the transfers to the second period, the credit constraint is alleviated to a lesser extent, and the optimal tax rate is lower as a result. The relative share of tax revenue that can be transferred to the first period increases if a higher interest rate ( $r$ higher) or more severe capital market failures ( $\pi$ higher) make intertemporal transfers less costly to the government than to households. The reason is that government faces a lower relative price for first-period consumption, i.e. $1+r$, than households, i.e. $\frac{1+r}{1-\pi}$.

Note that our efficiency case for progressive income taxation does not rely exclusively on the endogeneity of human capital investments. Indeed, the optimal income tax would be progressive even when human capital would be exogenous $(\beta=0)$. Therefore, we formally prove the numerical findings by Hubbard and Judd (1986) that optimal income taxes are progressive when individuals are borrowing constrained.

Furthermore, it can be seen that our results also do not rely on the assumption of fully non-deductible costs of education. If the costs of education would be fully tax deductible, income taxes would not distort human capital formation $\left(\beta \varepsilon_{e t}=0\right)$. Hence, income taxes 
remain positive, and they would even be higher than in the case of non-deductible costs, since the elasticity of the tax base would be smaller for a given distortion created by the credit constraint $\pi(1-\chi)$.

Even in the absence of redistributional concerns, the optimal labor tax rate is positive. The distortionary income tax helps to reduce a pre-existing non-tax distortion in capital markets. We thus provide second-best argument for employing distortionary income taxation for efficiency reasons. See also the introduction for references to the literature on efficient income taxation in models with rat-races and habit persistence, distorted labor markets, and missing insurance markets.

If investment in education and labor supply would both become perfectly inelastic, the labor tax would become completely non-distortionary and the first-best allocation could be obtained. The labor tax then has become a second-period lump-sum tax, which differs from the first-period lump-sum tax $g$. The results of this section are summarized in the following proposition.

Proposition 1. The optimal labor tax is positive for efficiency reasons when individuals are credit constrained. A redistributive income tax relaxes credit constraints because it transfers income from non-constrained towards constrained phases in the life-cycle. The optimal tax rate strikes a balance between the welfare gains from alleviating the credit constraints and the efficiency losses of distortionary taxation on labor supply and human capital investment.

\section{Optimal taxation with redistribution}

Until now we have shown the optimality of positive labor tax assuming identical individuals. In this section we allow the individuals to differ in their initial wealth $\omega$ and their innate ability $n$. By doing so, we introduce redistributional concerns in the optimal-tax problem. Since we assume that neither $\omega$ nor $n$ are observable to the government, individualized lump-sum transfers that are conditioned on either ability or initial wealth are excluded. Consequently, the government has to rely on distortionary labor income taxation to redistribute income between individuals.

Like before, revenues from the labor tax are used to finance the lump-sum transfers in both periods. Individualized lump-sum transfers that are conditioned on initial wealth and learning ability would be required to achieve a first-best outcome, which is not feasible due to the presumednon-observability of $\omega$ and $n$.

We can write the government budget constraint as

$$
t \int_{\underline{n}}^{\infty} \int_{\underline{\omega}}^{\infty} n l_{n \omega} \phi\left(e_{n \omega}\right) \mathrm{d} F(n, \omega)=(2+r) g .
$$


The government maximizes a social welfare function, which is a concave sum of individual indirect utilities $V_{n \omega}(g, t)$ :

$$
\int_{\underline{n}}^{\infty} \int_{\underline{\omega}}^{\infty} \Psi\left(V_{n \omega}(g, t)\right) \mathrm{d} F(n, \omega), \quad \Psi^{\prime}>0, \quad \Psi^{\prime \prime} \leq 0 .
$$

The social welfare function is utilitarian if $\Psi^{\prime}=1$, and it is Rawlsian if it features $\Psi^{\prime}=0$ for all individuals, except for the individual with the lowest utility.

We follow Diamond (1975) by defining the net social marginal valuation of one unit of income in both periods, measured in monetary units, for individuals with ability $n$ and initial wealth $\omega$ as:

$$
b_{n \omega}=\Psi^{\prime}\left(V_{n \omega}\right) \frac{u_{1}(\cdot)+u_{2}(\cdot)}{\eta}+t n l_{n \omega} \phi^{\prime}\left(e_{n \omega}\right) \frac{\partial e_{n \omega}}{\partial g}+\operatorname{tn} \phi\left(e_{n \omega}\right) \frac{\partial l_{n \omega}}{\partial g} .
$$

By using Roy's lemma the optimal lump-sum transfer $g$ is set such that (see Appendix A.4)

$$
\bar{b}=2+r,
$$

where $\bar{b} \equiv \int_{\underline{n}}^{\infty} \int_{\underline{\omega}}^{\infty} b_{n \omega} \mathrm{d} F(n, \omega)$ denotes the average social marginal value of income. The average social marginal valuation of one unit income in both periods equals its resource costs.

In order to characterize the optimal income tax, we define the distributional characteristic of labor income as (see Atkinson and Stiglitz, 1980)

$$
\xi=-\frac{\operatorname{cov}\left[b_{n \omega}, z_{n \omega}\right]}{\bar{b} \bar{z}}=1-\int_{\underline{n}}^{\infty} \int_{\underline{\omega}}^{\infty} \frac{b_{n \omega} z_{n \omega}}{\bar{b} \bar{z}} \mathrm{~d} F(n, \omega)>0,
$$

where $\bar{z}$ denotes average gross labor income, i.e. $\bar{z} \equiv \int_{\underline{n}}^{\infty} \int_{\underline{\omega}}^{\infty} z_{n \omega} \mathrm{d} F(n, \omega)$. The distributional characteristic $\xi$ measures the marginal increase in social welfare, expressed in monetary units as a fraction of taxed labor income, of a marginal redistribution through the tax system. $\xi$ is the (negative) normalized covariance between $b_{n \omega}$, the welfare weight of individual with ability $n$ and wealth $\omega$, and gross labor income $z_{n \omega}$. We (realistically) assume that the correlation between endowments and abilities is non-negative, and income effects are sufficiently small, so as to ensure that the distributional characteristic is always positive. That is, a positive value of $\xi$ implies that individuals with a higher gross labor income $z_{n \omega}$ have a lower social welfare weight $b_{n \omega}$. $\xi$ is therefore a measure for the strength of redistributional concerns implied by the social welfare function (23) given the amount of before-tax inequality. $\xi$ is zero if the social welfare weights $b_{n \omega}$ for all individuals are equal, so that the government does not want to redistribute any income, or if there is no inequality in labor earnings $z_{n \omega}$, so that taxing labor earnings does not 
redistribute (income differences can only arise from differences in initial wealth)..$^{7}$

The optimal labor tax $t$ can be expressed as (see Appendix A.4):

$$
\frac{t}{1-t}=\frac{\xi+\overline{\pi(1-\chi)}}{\overline{\varepsilon_{l t}}+\overline{\beta \varepsilon_{e t}}} \text {. }
$$

$\overline{\pi(1-\chi)} \equiv \int_{\underline{n}}^{\infty} \int_{\underline{\omega}}^{\infty} \frac{b_{n \omega} z_{n \omega}}{\bar{b} \bar{z}} \pi_{n \omega}\left(1-\chi_{n \omega}\right) d F(n, \omega)$ is a weighted average for the marginal welfare gain of relaxing the credit constraint where $b_{n \omega} z_{n \omega}$ is used as the weight. Similarly, $\overline{\varepsilon_{l t}} \equiv \int_{\underline{n}}^{\infty} \int_{\underline{\omega}}^{\infty} \frac{z_{n \omega} \varepsilon_{l t, n \omega}}{\bar{z}} d F(n, \omega)$ and $\overline{\beta \varepsilon_{e t}} \equiv \int_{\underline{n}}^{\infty} \int_{\underline{\omega}}^{\infty} \frac{z_{n \omega} \beta_{n \omega} \varepsilon_{e t, n \omega}}{\bar{z}} d F(n, \omega)$ denote the incomeweighted averages of the compensated labor supply elasticity and education elasticities, respectively.

Individuals with a different ability $n$ or a different initial wealth $\omega$ face different credit constraints. Therefore, the individual utility gains from relaxing the credit constraints differ across individuals. For individuals that are not constrained at all, the welfare gain of alleviating the credit constraint is zero $\left(\pi_{n \omega}=0\right) . \overline{\pi(1-\chi)}$ gives the average welfare gain - weighted by welfare weights and gross income - from alleviating potentially relevant credit constraints. The weighted average tax elasticities in labor and education capture the marginal efficiency costs of taxing labor income. Therefore, the optimal tax rate shows the trade-off between, on the one hand, the welfare gain from redistribution and alleviating the credit constraints and, on the other hand, the efficiency costs of taxing labor income.

In the presence of credit constraints, taxing labor income improves efficiency by encouraging educational investments and reducing the intertemporal distortions in consumption. As a result, the conflict between redistribution and efficiency is less severe, which can be seen by rewriting equation (27) as

$$
\frac{t}{1-t}\left(\overline{\varepsilon_{l t}}+\overline{\beta \varepsilon_{e t}}\right)-\overline{\pi(1-\chi)}=\xi
$$

The welfare gains from relaxing credit constraints reduce the efficiency costs of redistributive taxation and increases the optimal tax rate - for a given desire to redistribute income $\xi$. Even without any desire for income redistribution $(\xi=0)$, there is a positive labor tax rate, implying a case for distortionary taxation only on grounds of efficiency, as we have demonstrated above for homogenous individuals. When credit constraints are irrelevant, $(\overline{\pi(1-\chi)}=0)$, equation 27 reduces to the standard expression for the optimal linear income tax with endogenous human capital formation (see, for example, Jacobs, 2005; Bovenberg and Jacobs, 2005).

Although the welfare gains from redistribution $\xi$ and those from alleviating credit

\footnotetext{
${ }^{7}$ Because of the non-observability of initial wealth, the government cannot tax initial wealth to redistribute income. For individuals with same labor income, but different initial wealth levels, the distributional characteristic of labor income is zero although they feature different welfare weights $b_{n \omega}$. In this case, the government will not tax labor income because the labor tax cannot help to reduce inequality.
} 
constraints enter equation (27) additively, they cannot be separated when determining the optimal tax rate $t$. This can be seen by noting that $b_{n \omega}$ enters the term $\overline{\pi(1-\chi)}$ through the weights $b_{n \omega} z_{n \omega}$ for the individual utility gains from a weaker credit constraint. To gain further intuition, suppose that initial wealth is equally distributed. Then, higherability individuals feature lower social welfare weights $b_{n \omega}$, and they would be more credit constrained, because they invest more in education. The weighted average welfare gain $\overline{\pi(1-\chi)}$ is then lower than in the case without any redistributional concerns (where $b_{n \omega}$ is constant). The reason is that the welfare gains for relaxing the credit constraints at highability individuals are discounted by lower social welfare weights. Similarly, if individuals have a relatively lower income $z_{n \omega}$, the weights to discount credit constraints $z_{n \omega} b_{n \omega}$ also decrease. Credit constraints facing high-income individuals are more important than credit constraints facing low-income individuals, because alleviating credit constraints for them has larger efficiency effects.

If individuals would have identical abilities, but would differ only in initial wealth, individuals with lower initial wealth are more credit constrained and also have a larger welfare weight. As long as initial wealth is not observable, the government can achieve some redistribution by alleviating the credit constraint to a larger extent, since alleviating credit constraints helps the individuals with less initial wealth more than the ones with more initial wealth. The optimal tax rate is therefore higher when distributional concerns are present, compared to the case where they are absent. However, the effect of credit constraints on the optimal tax rate tends to be smaller if initial wealth and ability are more (positively) correlated. On the one hand, credit constraints are less severe, since high-ability individuals also have more initial wealth to finance their higher investment in education, i.e. $\pi_{n \omega}$ is lower. On the other hand, credit constraints for high-ability individuals are weighted less in view of the distributional concerns of the government.

We also note that, even without any desire to redistribute income, the optimal tax rate is not the same as that in (21). If the government has no distributional concerns ( $b_{n \omega}$ is constant), we have $\xi=0$. The optimal tax rate with heterogenous individuals is different than that with homogenous individuals, since the welfare gains and tax distortions are weighted by gross income. Similarly, the tax distortions of high-income earners are relatively more important than the tax distortions of low-income earners, because the elasticities are weighted with income. We summarize the results of this section in Proposition 2.

Proposition 2. The optimal tax rate trades-off the welfare gains from alleviating credit constraints and equity against the efficiency costs of the labor tax. The efficiency-enhancing effects of redistribution improve the trade-off between equity and efficiency. For given levels of initial wealth, the optimal income tax is lower if high-ability individuals are relatively more credit constrained and mitigating credit constraints results in larger inequality. For given levels of ability, redistributional concerns raise the income tax, since income 
inequality is reduced when credit constraints are less severe.

\section{$5 \quad$ Numerical examples}

In this section we provide some numerical simulations to illustrate the effects of credit constraints on optimal income taxes. The simulations require the following information: i) a joint distribution of abilities and initial wealth levels, ii) the utility function, iii) the production function for human capital, and iv) the social welfare function.

Initial wealth and ability are assumed to be jointly log-normally distributed with correlation coefficient $\rho$ between log-abilities and log-wealth levels. Log-normal distributions are useful first approximations to real-world income and wealth distributions. Log-wealth is normally distributed with mean $\mu_{\omega}$ and standard deviation $\sigma_{\omega}$. Log-ability is also normally distributed with mean $\mu_{n}$ and standard deviation $\sigma_{n}$. We construct a data set representing the deciles of each distribution to form 100 ability-wealth classes for the whole population. We assume that initial wealth and ability are positively correlated and set $\rho=0.25$ for the benchmark case. The correlation coefficient is chosen such that about one quarter of the population is credit constrained in the baseline simulation, see below.

The utility function is assumed to be separable in sub-utility from consumption in both periods and labor:

$$
\begin{aligned}
& U_{n \omega} \equiv\left[\alpha\left(c_{n \omega}^{1}\right)^{\delta}+(1-\alpha)\left(c_{n \omega}^{2}\right)^{\delta}\right]^{\frac{\nu}{\delta}}-\gamma \frac{l_{n \omega}^{1+1 / \varepsilon}}{1+1 / \varepsilon}, \\
& \gamma, \varepsilon>0, \quad 0<\alpha<1, \quad 0<\nu \leq 1, \quad-\infty<\delta<1 .
\end{aligned}
$$

The sub-utility function for consumption is a standard CES-function as in Mirrlees (1971) and Stern (1976). The constant elasticity of intertemporal substitution in consumption is equal to $\frac{1}{1-\delta}$. For the benchmark case we set $\delta=-0.5$ to obtain an intertemporal elasticity of substitution in consumption of 0.67 . This value lies in the middle of the range of empirical estimates provided by Guvenen (2006) and Attanasio and Weber (2010) in surveys of the literature.

In all simulations we assume a gross interest rate of $r=0.63$, which corresponds to an annual interest rate of $3.3 \%$ for a period of 15 years. $\alpha$ is a parameter denoting the relative importance of first-period consumption relative to second-period consumption. By setting $r=0.63$ and $\delta=-0.5$, we calibrate $\alpha=0.36$ to obtain an upward-sloping consumption path in the unconstrained optimum such that households on average consume twice as much in the second period as in the first.

The parameter $\nu \leq 1$ determines whether there are income effects in labor supply and education choices with perfect capital markets. If $\nu=1$, the sub-utility function of 
consumption is linearly homogenous, so that the marginal utility of income is constant and equal to one. In the benchmark case we will set $\nu=0.25$ to allow for income effects. The parameter $\varepsilon$ is the Frisch elasticity of labor supply and $\gamma$ is a parameter used to calibrate the disutility from work. The Frisch elasticity is higher than the compensated laborsupply elasticity (Blundell and MaCurdy, 1999). Empirical estimates of compensated labor-supply elasticities give values between 0.2 and 0.3 for men and much higher values of around 0.7 for women. We use a value of 0.25 for the benchmark case 8

The production function of human capital is assumed to be Cobb-Douglas:

$$
\phi\left(e_{n \omega}\right)=A e_{n \omega}^{\theta}, \quad A>0, \quad 0<\theta<1 .
$$

$A$ is a parameter denoting the productivity of educational investment and $\theta$ denotes the elasticity of human capital investments in $\phi$. Trostel (1993) uses $\theta=0.6$ and Jacobs (2005) uses $\theta=0.4$ for the investment share in the production of human capital. We have set $\theta=0.5$ for the benchmark case.

The social welfare function is a Bergson-Samuelson function with a constant elasticity of inequality aversion $\zeta$, see e.g. Atkinson and Stiglitz (1980):

$$
\Psi\left(V_{n \omega}\right)= \begin{cases}\frac{V_{n \omega}^{1-\zeta}-1}{1-\zeta}, & \zeta \neq 1, \\ \ln V_{n \omega}, & \zeta=1 .\end{cases}
$$

For $\zeta=0$, the social welfare function is utilitarian. If the individual utility function is in addition assumed to be linearly homogenous $(\nu=1)$, then there are no distributional concerns and distortionary taxation can only be justified on efficiency grounds. For $\zeta=\infty$, the welfare function converges to the Rawlsian maxi-min case. In our benchmark case, we use $\zeta=5$ to obtain optimal tax rates in the baseline that are in line with commonly observed values in the real world.

The remaining parameters - the distribution parameters $\mu_{n}, \mu_{\omega}, \sigma_{n}$, and $\sigma_{\omega}$, human capital productivity $A$ and disutility of labor $\gamma$ - are jointly calibrated to meet 3 conditions we impose on the model in the baseline. i) Mean labor supply in laissez faire equals 0.67 . This value is taken from Jacobs (2005), Stern (1976), and Tuomala (1990) and implies that an average individual spends two thirds of his/her time endowment working in the absence of taxation. ii) The Gini-coefficient of second-period consumption in laissez faire is 0.46 . OECD statistics show that the average Gini-coefficient of market incomes (before taxation) is around 0.46 from the mid-2000s until recent years. iii) 22 percent of the

\footnotetext{
${ }^{8}$ Blundell and MaCurdy (1999), Evers, De Mooij and van Vuuren (2008) survey the empirical literature on elasticity of labor supply. Estimates of the uncompensated labor-supply elasticity are on average between 0 and 0.1 for men and a much higher value around 0.5 for women. The income elasticity is often estimated with less precision, but the average of the estimates presented in Blundell and MaCurdy (1999) is around 0.2 for both men and women.
} 
population is credit constrained under optimal taxes. The share of population being credit constrained is estimated by Hall and Mishkin (1982) and Mariger (1986) at 20 percent. Jappelli (1990) also finds that around 20 percent of the U.S. households were credit constrained, using the Survey of Consumer Finances in 1983. We assume a higher standard deviation of initial wealth than that of ability given that wealth distributions are typically more unequal than income distributions. The calibration yields distribution parameters $\mu_{n}=3.5, \mu_{\omega}=5, \sigma_{n}=0.7$ and $\sigma_{\omega}=1$. The efficiency parameter $A$ is set to 1 and the labor parameter $\gamma$ is set to 1.8 .

We numerically solve for the individual maximization problem from the first-order conditions for each of the 100 ability-wealth cells using a (quasi) Newton algorithm. We employ a grid procedure for the tax rate over the range $[0.01 ; 0.80]$ and use the government budget constraint to solve for the lump-sum transfer for each tax rate. We then determine the tax rate (and transfer) that yields the (global) maximum of social welfare.

The parameter values used for the baseline simulation are summarized in Table 1 ;

Table 1: Parameter values for baseline simulation

\begin{tabular}{ll}
\hline \hline$\varepsilon=0.25$ & Frisch elasticity of labor supply \\
$\theta=0.5$ & elasticity of education investment \\
$\delta=-0.5$ & elasticity of intertemporal substitution \\
$\zeta=5$ & elasticity of inequality aversion \\
$\alpha=0.36$ & share of first-period consumption \\
$\nu=0.25$ & income effect parameter \\
$r=0.63$ & interest rate \\
$\gamma=1.8$ & labor dis-utility parameter \\
$A=1$ & muman capital production parameter \\
$\mu_{n}=3.5$ & standard deviation of log-ability \\
$\sigma_{n}=0.7$ & mean of log-wealth \\
$\mu_{\omega}=5$ & standard deviation of log-wealth \\
$\sigma_{\omega}=1$ & correlation coefficient \\
$\rho=0.25$ &
\end{tabular}

Table 2 provides the baseline simulation results. We simulate the model for the cases where there are binding credit constraints and where capital markets are assumed to be perfect. The shares of credit constrained individuals are denoted by $\Sigma$. The table provides the average levels of educational investment, labor supply and consumption in both periods. We also report the Gini coefficients for consumption. The level of social welfare $\mathcal{W}$ is given in the last column. The first and third columns in Table 1 provide the results in laissez faire, while the second and the fourth columns show the results with optimal taxation.

The optimal tax rate of 0.28 with perfect capital markets is significantly lower than the optimal tax rate of 0.39 with credit constraints. Thus, credit constraints contribute 
Table 2: Simulation results for the baseline with credit constraint and without credit constraints

\begin{tabular}{l|cc|cc}
\hline \hline & \multicolumn{2}{|c|}{ Binding credit constraints } & \multicolumn{2}{c}{ Perfect capital market } \\
& Laissez faire & Optimal taxation & Laissez faire & Optimal taxation \\
\hline$t$ & - & 0.39 & - & 0.28 \\
$T$ & - & 25.6 & - & 39.7 \\
$\Sigma$ & 0.53 & 0.22 & 0 & 0 \\
$\bar{e}$ & 45.4 & 26.9 & 203.1 & 82.4 \\
$\bar{l}$ & 0.67 & 0.55 & 0.75 & 0.61 \\
$\overline{c^{1}}$ & 125.6 & 131.6 & 190.7 & 165.5 \\
Gini $\left(c^{1}\right)$ & 0.46 & 0.40 & 0.48 & 0.38 \\
$\overline{c^{2}}$ & 312.3 & 281.4 & 387.6 & 336.4 \\
Gini $\left(c^{2}\right)$ & 0.45 & 0.39 & 0.48 & 0.38 \\
$\mathcal{W}$ & 0.2473 & 0.2479 & 0.2476 & 0.2484 \\
\hline
\end{tabular}

All parameters of the model take the values provided in Table 1 .

to substantially higher optimal income taxes. In laissez faire $53 \%$ of the total population would be credit constrained if individuals were not allowed to borrow on the capital market. With optimal taxes the number of credit-constrained individuals drops to $22 \%$. Nevertheless, educational investment and labor supply with optimal taxation are lower than in laissez faire, because of the distortionary effects of taxation. Compared to the case with perfect capital markets, credit constraints substantially distort educational investments and fist-period consumption downwards. Average educational investment is reduced by $75 \%$ and first-period consumption is on average reduced by one third. Because credit constraints reduce human capital investments, wages per hour worked are lower. The lower wages, in turn, discourage labor supply. In addition, credit constraints effectively raise second-period consumption, relative to first-period consumption. The associated wealth effect also reduces labor supply. In laissez faire there is more inequality with perfect capital markets than under borrowing constraints. For a given level of initial wealth, borrowing constraints especially hurt the high-ability individuals who optimally want to invest more resources in human capital than the low-ability individuals. This effect is partially mitigated by a positive correlation between initial wealth and ability. The Gini coefficient of second-period consumption in laissez faire increases by 0.03 and that of the first-period consumption increases by 0.02 , if capital markets are perfect.

How large would optimal income taxes be if the government was not interested in redistribution at all? In that case, income taxes are only employed for efficiency reasons and not for equity reasons. We simulate the economy for a pure efficiency case, where we adopt a utilitarian social objective $(\zeta=0)$ and assume a constant marginal utility of income at the household level $(\nu=1)$. To maintain comparability with our baseline simulations, we recalibrate the disutility of work parameter at $\gamma=300$ so as to keep average labor supply in laissez faire with credit constraints roughly the same (0.68). 
Table 3: Simulation results for the pure efficiency case under credit constraints

\begin{tabular}{l|cc}
\hline \hline & Laissez faire & Optimal taxation \\
\hline$t$ & - & 0.25 \\
$T$ & - & 22.6 \\
$\Sigma$ & 0.51 & 0.32 \\
$\bar{e}$ & 48.8 & 39.3 \\
$\bar{l}$ & 0.68 & 0.62 \\
$\overline{c^{1}}$ & 128.6 & 137.0 \\
Gini $\left(c^{1}\right)$ & 0.47 & 0.42 \\
$\overline{c^{2}}$ & 338.0 & 317.4 \\
Gini $\left(c^{2}\right)$ & 0.49 & 0.43 \\
$\mathcal{W}$ & 204.2 & 209.5 \\
\hline
\end{tabular}

All parameters of the model take the values provided in Table 1 , except for $\zeta=0, \nu=1$ and $\gamma=300$.

The results for the efficiency case are given in Table 3. The optimal tax rate for the pure efficiency case equals 0.25 , which is remarkably high, although lower than 0.39 when distributional concerns are included. Again, this simulation vindicates the potential efficiency-enhancing effects of progressive income taxes so as to reduce the adverse consequences of credit constraints. Due to redistributive income taxation, the share of credit-constrained individuals decreases from $51 \%$ to $32 \%$, while human capital investment and labor supply are only slightly reduced. On the one hand, credit constraints are alleviated, which promotes human capital investments, raises wages per hour worked, and hence boosts labor supply. On the other hand, income taxes naturally distort labor supply. Both effects roughly cancel out at the optimum. The Gini coefficients for consumptions in both periods are reduced as well, even though the motive for progressive income taxation is only to improve allocative efficiency.

We carried out various robustness checks by varying elasticity parameters, distributional parameters and the inequality aversion of the government. Table 4 provides the optimal tax rates where we compare the optimal policies with credit constraints to those obtained under a perfect capital market. The constrained population under optimal taxation $(\Sigma)$ is given in the last column, and the share of the population being constrained in laissez faire $\left(\Sigma^{L F}\right)$ is shown in parentheses.

From Table 4 we can see that the optimal tax rates with credit constraints are always higher than those with perfect capital markets, except for the case of $\theta=0.2$, where the optimal tax rate is the same in both cases. This is not very surprising, because the returns to education are so low that only $3 \%$ of the population is constrained in that case. Indeed, if $\theta=0.6$, the share of population being constrained in laissez faire rises to $86 \%$. Hence, taxation has to be more redistributive in order to slacken the credit constraints that have become more severe, despite the fact that distortions of taxation are larger when the 
Table 4: Simulation results optimal tax policy for different values for the elasticity of substitution, the Frisch elasticity of labor supply and the elasticity of human capital

\begin{tabular}{l|c|cc}
\hline \hline & $\begin{array}{c}\text { Perfect capital markets } \\
t(T)\end{array}$ & \multicolumn{2}{|c}{ Binding credit constraints } \\
& & & $\Sigma\left(\Sigma^{L F}\right)$ \\
\hline Base: $\delta=-0.5$ & $0.28(40.3)$ & $0.41(24.9)$ & $0.20(0.55)$ \\
$\delta=-3(\alpha=0.09)$ & $0.28(39.5)$ & $0.37(26.4)$ & $0.22(0.53)$ \\
$\delta=0.2(\alpha=0.48)$ & $0.28(39.4)$ & $0.36(27.3)$ & $0.24(0.55)$ \\
$\delta=0.5(\alpha=0.54)$ & $0.32(51.5)$ & $0.46(39.7)$ & $0.22(0.59)$ \\
\hline Base: $\varepsilon=0.25$ & $0.26(34.6)$ & $0.35(19.6)$ & $0.20(0.45)$ \\
$\varepsilon=0.1$ & $0.24(29.3)$ & $0.32(14.1)$ & $0.20(0.42)$ \\
$\varepsilon=0.35$ & $0.12(1.4)$ & $0.12(1.4)$ & $0.015(0.03)$ \\
$\varepsilon=0.5$ & $0.29(10.8)$ & $0.34(10.1)$ & $0.09(0.25)$ \\
\hline Base: $\theta=0.5$ & $0.26(335.5)$ & $0.5(68.9)$ & $0.35(0.86)$ \\
$\theta=0.2$ &
\end{tabular}

All parameters of the model take the values provided in Table 1, except where indicated otherwise.

human capital elasticity increases. When the intertemporal elasticity of substitution is increased, i.e. a larger $\delta$, the implicit tax due to credit constraints $\pi$ is smaller. Hence, the optimal tax rates are lower. The optimal tax rate under perfect capital markets does not change for different values of $\delta$. The reason is that the implicit tax of credit constraints on educational investments is zero. The optimal tax rate decreases with a higher elasticity of labor supply $\varepsilon$, since tax distortions on both labor supply and human capital investments increase. When the elasticity of human capital production $\theta$ increases, the optimal tax rate under credit constraints significantly increases, because the negative effects of borrowing constraints are larger when returns to human capital investments are larger and individuals wish to invest more.

Table 5 provides the simulation results for different distribution parameters for initial wealth and ability and for different degrees of inequality aversion. These simulations also demonstrate that optimal tax rates are higher when credit constraints are binding. When the distribution of ability becomes more dispersed, income inequality increases, and the optimal tax rate will be higher accordingly. However, a more unequal distribution of initial wealth has a much smaller effect on the optimal tax rate for the reason that taxing labor income cannot directly reduce inequality in initial wealth. When the correlation between initial wealth and ability becomes stronger, optimal tax rates fall slightly. Two opposing effects are at work here. First, especially individuals with higher abilities are credit constrained. When the correlation increases, the share of credit-constrained individuals decreases, and optimal tax rates fall for that reason. Second, a higher correlation between wealth and ability also implies more income inequality, which calls for a higher 
Table 5: Simulation results optimal tax policy for different values for distribution parameters and inequality aversion

\begin{tabular}{l|c|cc}
\hline \hline & Perfect capital markets & \multicolumn{2}{|c}{ Binding credit constraints } \\
& $t(T)$ & $t(T)$ & $\Sigma\left(\Sigma^{L F}\right)$ \\
\hline Base: $\sigma_{n}=0.7$ & & & \\
$\sigma_{n}=0$ & $0(0)$ & $0.16(7.0)$ & $0.40(0.50)$ \\
$\sigma_{n}=0.2$ & $0.04(3.1)$ & $0.18(8.3)$ & $0.33(0.52)$ \\
$\sigma_{n}=0.4$ & $0.18(14.4)$ & $0.27(13.3)$ & $0.27(0.52)$ \\
\hline Base: $\sigma_{\omega}=1$ & & & \\
$\sigma_{\omega}=0$ & $0.31(38.6)$ & $0.37(23.3)$ & $0.20(0.50)$ \\
$\sigma_{\omega}=0.5$ & $0.27(40.7)$ & $0.41(25.7)$ & $0.20(0.51)$ \\
$\sigma_{\omega}=2$ & $0.29(36.3)$ & $0.41(22.4)$ & $0.22(0.54)$ \\
\hline Base: $\rho=0.25$ & & & \\
$\rho=0$ & $0.27(40.6)$ & $0.39(23.3)$ & $0.25(0.52)$ \\
$\rho=0.5$ & $0.29(38.3)$ & $0.38(27.6)$ & $0.18(0.53)$ \\
$\rho=0.8$ & $0.30(36.1)$ & $0.35(30.6)$ & $0.10(0.55)$ \\
\hline Base: $\zeta=0.5$ & & \multicolumn{2}{|}{} \\
$\zeta=0$ & $0.20(34.1)$ & $0.35(24.4)$ & $0.26(0.53)$ \\
$\zeta=10$ & $0.31(40.8)$ & $0.41(26.0)$ & $0.20(0.53)$ \\
$\zeta=\infty$ & $0.36(41.6)$ & $0.50(26.9)$ & $0.15(0.53)$ \\
\hline
\end{tabular}

All parameters of the model take the values provided in Table 1, except where indicated otherwise.

tax rate from distributive concern. Both effects almost cancel out. When the preference for redistribution $(\zeta)$ increases, the optimal tax rate naturally increases. For a Rawlsian social welfare function, the optimal tax rate is the highest and equal to 0.50.

Finally, in order to illustrate the interaction between alleviating credit constraints and income redistribution, we compare the simulation results of two special cases: i) if initial wealth is uniformly distributed, and ii) if ability is uniformly distributed, both for different degrees of inequality aversion. Table 6 gives the optimal tax rates for different values of $\zeta$, when either $\sigma_{\omega}=0$ or $\sigma_{n}=0$.

Table 6: Optimal tax rates for uniformly distributed initial wealth or ability (optimal transfers in parentheses)

\begin{tabular}{l|cc}
\hline \hline & $\sigma_{n}=0$ & $\sigma_{\omega}=0$ \\
\hline$\zeta=0$ & $0.10(4.8)$ & $0.36(22.9)$ \\
$\zeta=5$ & $0.16(7.0)$ & $0.37(23.3)$ \\
$\zeta=10$ & $0.17(7.3)$ & $0.35(22.4)$ \\
$\zeta=\infty$ & $0.23(8.8)$ & $0.50(27.0)$ \\
\hline
\end{tabular}

All parameters of the model take the values provided in Table 1, except where indicated otherwise.

If all individuals have the same ability, the optimal tax rate with perfect capital 
markets is zero. In that case all individuals have the same labor income and redistributing labor income cannot improve income equality. When credit constraints are binding, progressive taxation is optimal to redistribute resources and to alleviate credit constraints. Such a policy helps the poorer individuals more than richer ones. Hence, the optimal tax rate also increases when the preference for redistribution becomes stronger. However, for $\sigma_{\omega}=0$, the pattern in optimal tax rates is not clear-cut if redistributional desires become stronger. On the one hand, a larger inequality aversion calls for a higher tax rate. On the other hand, a higher tax rate lifts credit constraints for the high-ability individuals, thereby generating larger inequality. The latter effect reduces the distributional benefits of a higher tax rate. The simulation results indeed show that the optimal tax rate might either increase or decrease.

\section{Conclusion}

This paper has formulated a two-period life-cycle model of saving, labor supply, and human capital investment when individuals differ in their ability and their initial wealth to analyze optimal income taxes. Binding borrowing constraints cause sub-optimal smoothing of consumption over the life-cycle and sub-optimal investment in human capital. We have demonstrated that the optimal linear income tax is always positive - even in the absence of redistributional concerns. A distortionary income tax is optimal because it relaxes borrowing constraints by redistributing resources from the unconstrained to the borrowing constrained stages of the life-cycle. Hence, redistribution allows for better consumption smoothing and larger investments in human capital. The progressive income tax is a second-best instrument to correct the non-tax distortion in the capital market. The equity-efficiency trade-off is therefore less severe when progressive income taxes mitigate capital market imperfections.

In future research, one may allow for partially verifiable human capital investments, which can be subsidized by governments (see also Bovenberg and Jacobs, 2005; Jacobs and Bovenberg, 2011). Consequently, it is interesting to explore how the optimal mix of income taxes and education subsidies is affected by binding credit constraints. Education subsidies also reduce the adverse effects of credit constraints on human capital investment. Optimal income taxes might become less progressive as a result. However, education subsidies also alleviate distortions of income taxation, so that optimal income taxes could increase for that reason (Bovenberg and Jacobs, 2005).

Furthermore, one could analyze the optimal setting of capital income taxes in the model with borrowing constraints. We expect that capital taxes are positive. Aiyagari (1995) has shown that, with binding credit constraints, capital taxes are optimally positive in infinite horizon Ramsey models. Hubbard and Judd (1986) showed that this is also true in life-cycle models. Jacobs and Bovenberg (2010) demonstrated that capital taxes 
are optimally positive even in the absence of binding credit constraints, since the capital tax reduces the disincentives of the labor tax on human capital investments. Probably, the case for a positive capital income tax survives when credit constraints are allowed for.

\section{A Appendix}

\section{A.1 Second-order conditions}

We derive first the second-order conditions of the household's maximization problem when credit constraints are slack and then when credit constraints are binding.

\section{A.1.1 Slack credit constraint}

We employ a two-step budgeting procedure to derive the second-order conditions. We assume linear homogenous sub-utility in consumption $u$ over $c^{1}$ and $c^{2}$ and we define the real price-index for consumption $p_{c}$ such that $p_{c} \equiv \frac{c_{n \omega}^{2}+(1+r) c_{n \omega}^{1}}{u\left(c_{n \omega}^{1}, c_{n \omega}^{2}\right)}$. Due to homogeneity the consumption price $p_{c}$ is independent of $n$ and $\omega$. Using the budget constraint

$$
(1+r) c_{n \omega}^{1}+c_{n \omega}^{2}=(1-t) n \phi\left(e_{n \omega}\right) l_{n \omega}+(1+r)\left(-e_{n \omega}+\omega+g\right)+g
$$

we can rewrite the individual maximization problem as an unconstrained maximization problem:

$$
\max _{\left\{e_{n \omega}, l_{n \omega}\right\}} \frac{(1-t) n \phi\left(e_{n \omega}\right) l_{n \omega}}{p_{c}}+\frac{(1+r)\left(-e_{n \omega}+\omega+g\right)+g}{p_{c}}-v\left(l_{n \omega}\right) .
$$

The first-order conditions are given by

$$
\begin{gathered}
(1-t) n \phi^{\prime}\left(e_{n \omega}\right) l_{n \omega}-(1+r)=0 \\
(1-t) n \phi\left(e_{n \omega}\right)-v^{\prime}\left(l_{n \omega}\right) p_{c}=0 .
\end{gathered}
$$

Hence, the Hessian matrix with second-order derivatives is

$$
H \equiv\left[\begin{array}{cc}
(1-t) n \phi^{\prime \prime} l_{n \omega} & (1-t) n \phi^{\prime} \\
(1-t) n \phi^{\prime} & -v^{\prime \prime} p_{c}
\end{array}\right]
$$

The first principal minor, $(1-t) n \phi^{\prime \prime} l_{n \omega}$ is negative, because by assumption $\phi^{\prime \prime}\left(e_{n \omega}\right)<0$. Therefore, for the Hessian to be negative semi-definite, the second principal minor should be positive:

$$
-(1-t) n \phi^{\prime \prime} l_{n \omega} v^{\prime \prime} p_{c}-\left((1-t) n \phi^{\prime}\right)^{2}>0 .
$$


By defining the wage elasticity of labor supply as $\varepsilon_{n \omega} \equiv\left(\frac{v^{\prime \prime}\left(l_{n \omega}\right) l_{n \omega}}{v^{\prime}\left(l_{n \omega}\right)}\right)^{-1}$, the elasticity of human capital production function as $\beta_{n \omega} \equiv \frac{\phi^{\prime}\left(e_{n \omega}\right) e_{n \omega}}{\phi\left(e_{n \omega}\right)}$, the elasticity of the marginal return to education as $\alpha_{n \omega} \equiv \frac{\phi^{\prime \prime}\left(e_{n \omega}\right) e_{n \omega}}{\phi^{\prime}\left(e_{n \omega}\right)}$, and using the first-order condition for labor supply, we can rewrite the above inequality as

$$
\alpha_{n \omega}+\beta_{n \omega} \varepsilon_{n \omega}<0
$$

Since human capital production function is concave $\left(\phi^{\prime \prime}\left(e_{n \omega}\right)<0\right), \alpha_{n \omega}$ is negative. The second-order condition thus requires that the elasticity of labor supply and the elasticity of human capital production function should be sufficiently small and the elasticity of the marginal return to education is sufficiently large (in absolute terms) so as to avoid corner solutions. In the second stage of the budgeting procedure, individuals maximize $u\left(c_{n \omega}^{1}, c_{n \omega}^{2}\right)$ subject to the constraint $p_{c} u\left(c_{n \omega}^{1}, c_{n \omega}^{2}\right)=(1+r) c_{n \omega}^{1}+c_{n \omega}^{2}$. The associated second-order condition $u_{11}(\cdot) u_{22}(\cdot)-u_{12}^{2}(\cdot) \geq 0$ is always satisfied since $u(\cdot)$ is assumed to be strictly concave.

\section{A.1.2 Binding credit constraint}

With a binding credit constraint, savings are zero $(a=0)$. Hence, we can again obtain an unconstrained maximization problem upon substitution of budget constraints in the utility function:

$$
\max _{\left\{e_{n \omega}, l_{n \omega}\right\}} u\left(-e_{n \omega}+\omega+g,(1-t) n \phi\left(e_{n \omega}\right) l_{n \omega}+g\right)-v\left(l_{n \omega}\right) .
$$

The first-order conditions are given by

$$
\begin{aligned}
-u_{1}(\cdot)+u_{2}(\cdot)(1-t) n \phi^{\prime}\left(e_{n \omega}\right) l_{n \omega} & =0, \\
u_{2}(\cdot)(1-t) n \phi\left(e_{n \omega}\right)-v^{\prime}\left(l_{n \omega}\right) & =0 .
\end{aligned}
$$

The Hessian matrix $H$ with second-order partial derivatives is given by

$$
H \equiv\left[\begin{array}{cc}
u_{11}-2 u_{12}(1-t) n \phi^{\prime} l_{n \omega} & -u_{12}(1-t) n \phi+u_{22}(1-t)^{2} n^{2} \phi \phi^{\prime} l_{n \omega} \\
+u_{22}\left((1-t) n \phi^{\prime} l_{n \omega}\right)^{2}+u_{2}(1-t) n \phi^{\prime \prime} l_{n \omega} & +u_{2}(1-t) n \phi^{\prime} \\
-u_{12}(1-t) n \phi+u_{22}(1-t)^{2} n^{2} \phi \phi^{\prime} l_{n \omega} & u_{22}((1-t) n \phi)^{2}-v^{\prime \prime}\left(l_{n \omega}\right) \\
+u_{2}(1-t) n \phi^{\prime} &
\end{array}\right]
$$

For the Hessian matrix to be negative semi-definite, the principal minors should switch signs. The first principal minor

$$
u_{11}-2 u_{12}(1-t) n \phi^{\prime} l_{n \omega}+u_{22}\left((1-t) n \phi^{\prime} l_{n \omega}\right)^{2}+u_{2}(1-t) n \phi^{\prime \prime} l_{n \omega}<0
$$


is negative since all terms of (43) are negative under the assumptions that the consumption utility function is concave in both arguments $\left(u_{11}<0, u_{22}<0\right)$, the human capital production function is concave $\left(\phi^{\prime \prime}<0\right)$, and consumption in two periods are complementary $\left(u_{12} \geq 0\right)$. The second principal minor should therefore be positive:

$$
\begin{aligned}
& \left(u_{11}-2 u_{12}(1-t) n \phi^{\prime} l_{n \omega}+u_{22}\left((1-t) n \phi^{\prime} l_{n \omega}\right)^{2}+u_{2}(1-t) n \phi^{\prime \prime} l_{n \omega}\right) \times\left(u_{22}((1-t) n \phi)^{2}-v^{\prime \prime}\right) \\
& -\left(-u_{12}(1-t) n \phi+u_{22}(1-t)^{2} n^{2} \phi \phi^{\prime} l_{n \omega}+u_{2}(1-t) n \phi^{\prime}\right)^{2}>0 .
\end{aligned}
$$

Use the first-order conditions 40 and 41 and the definitions $\varepsilon_{n \omega} \equiv\left(\frac{v^{\prime \prime}\left(l_{n \omega}\right) l_{n \omega}}{v^{\prime}\left(l_{n \omega}\right)}\right)^{-1}$, $\beta_{n \omega} \equiv \frac{\phi^{\prime}\left(e_{n \omega}\right) e_{n \omega}}{\phi\left(e_{n \omega}\right)}$ and $\alpha_{n \omega} \equiv \frac{\phi^{\prime \prime}\left(e_{n \omega}\right) e_{n \omega}}{\phi^{\prime}\left(e_{n \omega}\right)}$ to reformulate the above inequality as

$$
\begin{aligned}
& u_{11} u_{22}+\frac{\alpha_{n \omega}}{e_{n \omega}} u_{22} u_{1}-\frac{u_{2}}{\varepsilon_{n \omega}} \frac{\beta_{n \omega}}{e_{n \omega}}\left(u_{11} \frac{u_{2}}{u_{1}}-2 u_{12}+u_{22} \frac{u_{1}}{u_{2}}+u_{2} \frac{\alpha_{n \omega}}{e_{n \omega}}\right) \\
& >u_{12}^{2}+\left(u_{2} \frac{\beta_{n \omega}}{e_{n \omega}}\right)^{2}-2 u_{12} u_{2} \frac{\beta_{n \omega}}{e_{n \omega}}+2 u_{22} u_{1} \frac{\beta_{n \omega}}{e_{n \omega}} .
\end{aligned}
$$

In deriving the second-order conditions, we assume that the utility function is linear homogenous and we use the properties $u_{11}(\cdot) c_{1}=-u_{12}(\cdot) c_{2}$ and $u_{12}(\cdot) c_{1}=-u_{22}(\cdot) c_{2}$ to find:

$$
u_{11}(\cdot) u_{22}(\cdot)-u_{12}^{2}(\cdot)=0
$$

Using (46) we can rewrite 45) as

$$
\alpha_{n \omega}+\beta_{n \omega} \varepsilon_{n \omega}<-\frac{u_{22} u_{1} e_{n \omega}}{u_{2}^{2}}\left(1-\frac{\alpha_{n \omega} \varepsilon_{n \omega}}{\beta_{n \omega}}+2 \varepsilon_{n \omega}\right)-\frac{u_{11} e_{n \omega}}{u_{1}}+2 \frac{u_{12} e_{n \omega}}{u_{2}}\left(\varepsilon_{n \omega}+1\right) .
$$

Because $u_{22}<0, u_{11}<0$ and $\alpha_{n \omega}<0$, the right-hand-side of equation (47) is always positive. Consequently,

$$
\alpha_{n \omega}+\beta_{n \omega} \varepsilon_{n \omega}<0
$$

is sufficient for 47) to be fulfilled. Therefore, $\alpha_{n \omega}+\beta_{n \omega} \varepsilon_{n \omega}<0$ is the sufficient secondorder condition for the households' maximization problem for both the cases of slack and binding credit constraints.

\section{A.2 Slutsky equations}

In order to derive the expected utility-compensated substitution effects, we calculate how much lump-sum income $g$ an individual should receive (pay) in both periods in order to keep its utility constant $\left(\mathrm{d} U_{n \omega}=0\right)$ when the tax rate $t$ changes. This is equivalent to deriving the expenditure function and applying Shephard's lemma. Totally differentiating 
the utility function (5) and the budget constraints (1) and (4) yields

$$
\begin{aligned}
\mathrm{d} U_{n \omega} & =u_{1}(\cdot) \mathrm{d} c_{n \omega}^{1}+u_{2}(\cdot) \mathrm{d} c_{n \omega}^{2}-v^{\prime}\left(l_{n \omega}\right) \mathrm{d} l_{n \omega}=0, \\
\mathrm{~d} c_{n \omega}^{1} & =-\mathrm{d} e_{n \omega}+\mathrm{d} \omega+\mathrm{d} g-\mathrm{d} a_{n \omega}, \\
\mathrm{d} c_{n \omega}^{2} & =(1-t) n l_{n \omega} \phi^{\prime}\left(e_{n \omega}\right) \mathrm{d} e_{n \omega}+(1-t) n \phi\left(e_{n \omega}\right) \mathrm{d} l_{n \omega}-n l_{n \omega} \phi\left(e_{n \omega}\right) \mathrm{d} t \\
& +(1+r) \mathrm{d} a_{n \omega}+\mathrm{d} g .
\end{aligned}
$$

Substitute $\mathrm{d} c_{n \omega}^{1}$ and $\mathrm{d} c_{n \omega}^{2}$ in $\mathrm{d} U_{n \omega}$ to find

$$
\begin{aligned}
\mathrm{d} U_{n \omega} & =\left(u_{2}(\cdot)(1-t) n l_{n \omega} \phi^{\prime}\left(e_{n \omega}\right)-u_{1}(\cdot)\right) \mathrm{d} e_{n \omega}+u_{1} \mathrm{~d} \omega \\
& +\left(u_{1}(\cdot)+u_{2}(\cdot)\right) \mathrm{d} g+\left(u_{2}(\cdot)(1+r)-u_{1}(\cdot)\right) \mathrm{d} a_{n \omega} \\
& +\left(u_{2}(\cdot)(1-t) n \phi\left(e_{n \omega}\right)-v^{\prime}\left(l_{n \omega}\right)\right) \mathrm{d} l_{n \omega}-u_{2}(\cdot) n l_{n \omega} \phi\left(e_{n \omega}\right) \mathrm{d} t=0
\end{aligned}
$$

$\left(u_{2}(\cdot)(1-t) n l_{n \omega} \phi^{\prime}\left(e_{n \omega}\right)-u_{1}(\cdot)\right) \mathrm{d} e_{n \omega}$ and $\left(u_{2}(\cdot)(1-t) n \phi\left(e_{n \omega}\right)-v^{\prime}\left(l_{n \omega}\right)\right) \mathrm{d} l_{n \omega}$ are both equal to zero from the first-order conditions. The term $\left(u_{2}(\cdot)(1+r)-u_{1}(\cdot)\right) \mathrm{d} a_{n \omega}$ is equal to zero as well both in case of a binding credit constraint $\left(\mathrm{d} a_{n \omega}=0\right)$ and a slack credit constraint $\left(u_{2}(\cdot)(1+r)-u_{1}(\cdot)=0\right)$. Thus, we have

$$
\mathrm{d} U_{n \omega}=-u_{2}(\cdot) n l_{n \omega} \phi\left(e_{n \omega}\right) \mathrm{d} t+u_{1}(\cdot) \mathrm{d} \omega+\left(u_{1}(\cdot)+u_{2}(\cdot)\right) \mathrm{d} g=0 .
$$

For utility compensation through a higher transfer given in both periods, the Slutsky equations are thus given by

$$
\begin{aligned}
\frac{\partial e_{n \omega}}{\partial t} & =\frac{\partial e_{n \omega}^{c}}{\partial t}-\frac{u_{2}(\cdot) n l_{n \omega} \phi\left(e_{n \omega}\right)}{u_{1}(\cdot)+u_{2}(\cdot)} \frac{\partial e_{n \omega}}{\partial g} \\
\frac{\partial l_{n \omega}}{\partial t} & =\frac{\partial l_{n \omega}^{c}}{\partial t}-\frac{u_{2}(\cdot) n l_{n \omega} \phi\left(e_{n \omega}\right)}{u_{1}(\cdot)+u_{2}(\cdot)} \frac{\partial l_{n \omega}}{\partial g} .
\end{aligned}
$$

\section{A.3 Optimal taxation without redistribution}

The first-order conditions for the government's maximization problem are given by

$$
\begin{aligned}
& \frac{\partial \mathcal{W}}{\partial g}=u_{1}(\cdot)+u_{2}(\cdot)-\eta(2+r)+\eta\left(\operatorname{tnl} \phi^{\prime}(e) \frac{\partial e}{\partial g}+\operatorname{tn} \phi(e) \frac{\partial l}{\partial g}\right)=0 \\
& \frac{\partial \mathcal{W}}{\partial t}=-u_{2}(\cdot) n l \phi(e)+\eta n l \phi(e)+\eta\left(\operatorname{tnl} \phi^{\prime}(e) \frac{\partial e}{\partial t}+\operatorname{tn} \phi(e) \frac{\partial l}{\partial t}\right)=0 .
\end{aligned}
$$

Using the Slutsky-equations (54) and (55) we can derive from (56) that

$$
\frac{u_{1}(\cdot)+u_{2}(\cdot)}{\eta}+\operatorname{tnl} \phi^{\prime}(e) \frac{\partial e}{\partial g}+\operatorname{tn} \phi(e) \frac{\partial l}{\partial g}=2+r
$$


Using the definitions of the compensated elasticities $\varepsilon_{l t} \equiv-\frac{\partial l^{c}}{\partial t} \frac{1-t}{l}$ and $\varepsilon_{e t} \equiv-\frac{\partial e^{c}}{\partial t} \frac{1-t}{e}, 57$. can be rewritten as

$-\frac{u_{2}(\cdot)}{u_{1}(\cdot)+u_{2}(\cdot)}\left(\frac{u_{1}(\cdot)+u_{2}(\cdot)}{\eta}+\operatorname{tnl} \phi^{\prime}(e) \frac{\partial e}{\partial g}+\operatorname{tn} \phi(e) \frac{\partial l}{\partial g}\right)+1-\frac{t}{1-t} \frac{\phi^{\prime}(e) e}{\phi(e)} \varepsilon_{e t}-\frac{t}{1-t} \varepsilon_{l t}=0$.

Using (58) and $\frac{u_{1}}{u_{2}}=\frac{1+r}{1-\pi}$ we find

$$
\frac{t}{1-t}=\frac{\pi \frac{1+r}{2+r-\pi}}{\varepsilon_{l t}+\beta \varepsilon_{e t}}=\frac{\pi(1-\chi)}{\varepsilon_{l t}+\beta \varepsilon_{e t}}
$$

where $\beta \equiv \frac{\phi^{\prime}(e) e}{\phi(e)}$ is the elasticity of human capital production function and $\chi \equiv \frac{1-\pi}{2+r-\pi}$.

\section{A.4 Optimal taxation with redistribution}

This appendix derives the optimal taxation when agents differ in initial wealth and abilities and when the government does not have access to age-specific transfers. The Lagrangian for the government's maximization problem is:

$$
\max _{\{g, t\}} \mathcal{W} \equiv \int_{\underline{n}}^{\infty} \int_{\underline{\omega}}^{\infty}\left(\Psi\left(V_{n \omega}(g, t)\right)+\eta\left(t n l_{n \omega} \phi\left(e_{n \omega}\right)-(2+r) g\right)\right) \mathrm{d} F(n, \omega) .
$$

The first-order conditions are:

$$
\begin{aligned}
\frac{\partial \mathcal{W}}{\partial g} & =\int_{\underline{n}}^{\infty} \int_{\underline{\omega}}^{\infty}\left[\Psi^{\prime}\left(V_{n \omega}\right) \frac{\partial V_{n \omega}}{\partial g}-\eta(2+r)\right] \mathrm{d} F(n, \omega) \\
& +\int_{\underline{n}}^{\infty} \int_{\underline{\omega}}^{\infty}\left[\eta t\left(n l_{n \omega} \phi^{\prime}\left(e_{n \omega}\right) \frac{\partial e_{n \omega}}{\partial g}+n \phi\left(e_{n \omega}\right) \frac{\partial l_{n \omega}}{\partial g}\right)\right] \mathrm{d} F(n, \omega)=0 \\
\frac{\partial \mathcal{W}}{\partial t} & =\int_{\underline{n}}^{\infty} \int_{\underline{\omega}}^{\infty}\left[\Psi^{\prime}\left(V_{n \omega}\right) \frac{\partial V_{n \omega}}{\partial t}+\eta n l_{n \omega} \phi\left(e_{n \omega}\right)\right] \mathrm{d} F(n, \omega) \\
& +\int_{\underline{n}}^{\infty} \int_{\underline{\omega}}^{\infty}\left[\eta t\left(n l_{n \omega} \phi^{\prime}\left(e_{n \omega}\right) \frac{\partial e_{n \omega}}{\partial t}+n \phi\left(e_{n \omega}\right) \frac{\partial l_{n \omega}}{\partial t}\right)\right] \mathrm{d} F(n, \omega)=0 .
\end{aligned}
$$

Using Roy's lemma, (56) can be written as

$$
\int_{\underline{n}}^{\infty} \int_{\underline{\omega}}^{\infty}\left(\Psi^{\prime}\left(V_{n \omega}\right) \frac{u_{1}(\cdot)+u_{2}(\cdot)}{\eta}+t n l_{n \omega} \phi^{\prime}\left(e_{n \omega}\right) \frac{\partial e_{n \omega}}{\partial g}+\operatorname{tn} \phi\left(e_{n \omega}\right) \frac{\partial l_{n \omega}}{\partial g}\right) \mathrm{d} F(n, \omega)=2+r .
$$

Define $b_{n \omega} \equiv \Psi^{\prime}\left(V_{n \omega}\right) \frac{u_{1}(\cdot)+u_{2}(\cdot)}{\eta}+t n l_{n \omega} \phi^{\prime}\left(e_{n \omega}\right) \frac{\partial e_{n \omega}}{\partial g}+t n \phi\left(e_{n \omega}\right) \frac{\partial l_{n \omega}}{\partial g}$ as the marginal social valuation of one unit income for individuals with ability $n$ and initial wealth $\omega$. We derive

$$
\bar{b}=2+r,
$$


where $\bar{b} \equiv \int_{\underline{n}}^{\infty} \int_{\underline{\omega}}^{\infty} b_{n \omega} \mathrm{d} F(n, \omega)$. Using Roy's lemma $\frac{\partial V_{n \omega}}{\partial t}=-u_{2}(\cdot) n l_{n \omega} \phi\left(e_{n \omega}\right)$, definitions of the compensated elasticities $\varepsilon_{l t, n \omega} \equiv-\frac{\partial l_{n \omega}^{c}}{\partial t} \frac{1-t}{l_{n \omega}}$ and $\varepsilon_{e t, n \omega} \equiv-\frac{\partial e_{n \omega}^{c}}{\partial t} \frac{1-t}{e_{n \omega}}$, the Slutskyequations (54) and 55,, $\bar{b}=2+r$ and $\frac{u_{1}(\cdot)}{u_{2}(\cdot)}=\frac{1+r}{1-\pi_{n \omega}}$ we can rewrite equation 63) as

$$
\int_{\underline{n}}^{\infty} \int_{\underline{\omega}}^{\infty}\left(-\frac{b_{n \omega} z_{n \omega}}{\bar{b}}\left(1-\frac{\pi_{n \omega}}{1+\frac{1-\pi_{n \omega}}{1+r}}\right)-\frac{t}{1-t} z_{n \omega}\left(\beta_{n \omega} \varepsilon_{e t, n \omega}+\varepsilon_{l t, n \omega}\right)\right) \mathrm{d} F(n, \omega)+\bar{z}=0,
$$

where $\bar{z} \equiv \int_{\underline{n}}^{\infty} \int_{\underline{\omega}}^{\infty} z_{n \omega} \mathrm{d} F(n, \omega) \equiv \int_{\underline{n}}^{\infty} \int_{\underline{\omega}}^{\infty} n l_{n \omega} \phi\left(e_{n \omega}\right) \mathrm{d} F(n, \omega)$ is average labor income in the economy and $\beta_{n \omega} \equiv \frac{\phi^{\prime}\left(e_{n \omega}\right) e_{n \omega}}{\phi\left(e_{n \omega}\right)}$ denotes the elasticity of the human capital production function for individuals with ability $n$ and initial wealth $\omega$. We define the distributional characteristic as $\xi \equiv-\frac{\operatorname{cov}\left[b_{n \omega}, z_{n \omega}\right]}{\bar{b} \bar{z}}=1-\int_{\underline{n}}^{\infty} \int_{\underline{\omega}}^{\infty} \frac{b_{n \omega} z_{n \omega}}{\bar{b} \bar{z}} \mathrm{~d} F(n, \omega)$, which measures the social concern for redistribution. The first-order condition $(63)$ can be further simplified to

$$
\xi+\overline{\pi(1-\chi)}=\frac{t}{1-t}\left(\overline{\beta \varepsilon_{e t}}+\overline{\varepsilon_{l t}}\right)
$$

where $1-\chi_{n \omega} \equiv \frac{1+r}{2+r-\pi_{n \omega}}$ and we define $\overline{\pi(1-\chi)} \equiv \int_{\underline{n}}^{\infty} \int_{\underline{\omega}}^{\infty} \frac{b_{n \omega} z_{n \omega}}{\bar{b} \bar{z}} \pi_{n \omega}\left(1-\chi_{n \omega}\right) \mathrm{d} F(n, \omega)$ as the weighted average of the welfare gain from alleviating the credit constraint and $\overline{\beta \varepsilon_{\text {et }}} \equiv$ $\int_{\underline{n}}^{\infty} \int_{\underline{\omega}}^{\infty} \frac{z_{n \omega}}{\bar{z}} \beta_{n \omega} \varepsilon_{e t, n \omega} \mathrm{d} F(n, \omega)$ and $\overline{\varepsilon_{l t}} \equiv \int_{\underline{n}}^{\infty} \int_{\underline{\omega}}^{\infty} \frac{z_{n \omega}}{\bar{z}} \varepsilon_{l t, n \omega} \mathrm{d} F(n, \omega)$ denote the weightedaverage elasticities of human capital and labor supply. The optimal tax rate can be therefore characterized by

$$
\frac{t}{1-t}=\frac{\xi+\overline{\pi(1-\chi)}}{\overline{\beta \varepsilon_{e t}}+\overline{\varepsilon_{l t}}}
$$

\section{References}

Acemoglu, D. and J. S. Pischke (2001), Changes in the Wage Structure, Family Income, and Children's Education, European Economic Review, Vol. 45, No. 4-6, pp. 890904.

Aiyagari, S. R. (1995), Optimal Capital Income Taxation with Incomplete Markets, Borrowing Constraints, and Constant Discounting, Journal of Political Economy, Vol.103, No. 6, pp. 1158-1175.

Akerlof, G. (1976), The Economics of Caste and of the Rat Race and Other Woeful Tales, Quarterly Journal of Economics, Vol. 90, No. 4, pp. 599-617.

Anderberg, D. (2009), Optimal Policy and the Risk-Properties of Human Capital Reconsidered, Journal of Public Economics, Vol. 93, No. 9-10, pp. 1017-1026.

Anderberg, D., and F. Andersson (2003), Investments in Human Capital, Wage Uncertainty, and Public Policy, Journal of Public Economics, Vol. 87, No. 7-8, pp. 1521-1537. 
Atkinson, A. B. and J. E. Stiglitz (1980), Lectures on Public Economics, New York, McGraw-Hill.

Attanasio, O. P. and G. Weber (2010), Consumption and Saving: Models of Intertemporal Allocation and their Implications for Public Policy, Journal of Economic Literature, Vol. 48, No. 3, pp. 693-751.

Belley, P. and L. Lochner (2007), The Changing Role of Family Income and Ability in Determining Educational Achievement, Journal of Human Capital, Vol. 1, No.1, pp. 37-89.

Benabou, R. (1996a), Heterogeneity, Stratification, and Growth: Macroeconomic Implications of Community Structure and School Finance, The American Economic Review, Vol. 86, No. 3, pp. 584-609.

Benabou, R. (1996b), Equity and Efficiency in Human Capital Investment: The Local Connection, Review of Economic Studies, Vol. 63, No. 2, pp. 237-264.

Blundell R. and T. MaCurdy (1999), Labor Supply: A Reviw of Alternative Approaches, in O. Ashenfelter and D. Card (eds.), Handbook of Labor Economics, Vol. 3A, Chap 27, Amsterdam, North Holland.

Boone, J. and A. L. Bovenberg (2002), Optimal Labour Taxation and Search, Journal of Public Economics, Vol. 85, No. 1, pp. 53-97.

Bovenberg, A. L. (2006), Tax Policy and Labor Market Performance, in: Agell J. and P. Srensen (Eds.), Tax Policy and Labour Market Performance, CESifo and MIT Press, Cambridge, Mass.

Bovenberg, A. L. and B. Jacobs (2005), Redistribution and Education Subsidies are Siamese Twins, Journal of Public Economics, Vol. 89, No. 11-12, pp. 2005-2035.

Caneiro, P. and J. J. Heckman (2002), The Evidence on Credit Constraints in Postsecondary Schooling, The Economic Journal, Vol. 112, No. 482, pp. 705-734.

De Gregorio, J. (1996), Borrowing Constraints, Human Capital Accumulation, and Growth, Journal of Monetary Economics, Vol. 37, No. 1, pp. 49-71.

Diamond, P. A. (1975), A Many-Person Ramsey Tax Rule, Journal of Public Economics, Vol. 4, No. 4, pp. 335-342.

Durlauf, S. N. (1996), A Theory of Persistent Income Inequality, Journal of Economic Growth, Vol. 1, No. 1, pp. 75-93. 
Eaton, J., and H.S. Rosen (1980), Taxation, Human Capital, and Uncertainty, American Economic Review, Vol. 70, No. 4, pp. 705-715.

Evers. M, R. De Mooij and D. van Ruuren (2008), The Wage Elasticity of Labour Supply: A Synthesis of Empirical Estimates, De Economist, Vol. 156, No. 1, pp 26-43.

Fernandez, R. and R. Rogerson (1996), Income Distribution, Communities, and the Quality of Public Education, The Quarterly Journal of Economics, Vol. 111, No. 1, pp. 135-164.

Fernandez, R. and R. Rogerson (1998), Public Education and Income Distribution: A Dynamic Quantitative Evaluation of Education-Finance Reform, The American Economic Review, Vol. 88, No. 4, pp. 813-833.

Galor, O. and O. Moav (2004), From Physical to Human Capital Accumulation: Inequality an the Process of Development, Review of Economic Studies, Vol. 71, No. 4, pp. 1001-1026.

Galor, O. and J. Zeira (1993), Income Distribution and Macroeconomics, Review of Economic Studies, Vol. 60, No. 1, pp. 35-52.

Glomm, G. and B. Ravikumar (1992), Public versus Private Investment in Human Capital: Endogenous Growth and Income Inequality, Journal of Political Economy, Vol. 100, No. 4, pp. 818-834.

Guvenen, F. (2006), Reconciling Conflicting Evidence on the Elasticity of Intertemporal Substitution: A Macroeconomic Perspective, Journal of Monetary Economics, Vol. 53, No. 7, pp. 1451-1472.

Hall, R. E. and F. S. Mishkin (1982), The Sensitivity of Consumption to Transitory Income: Estimates from Panel Data on Households, Econometrica, Vol. 50, No.2, pp. 461-481.

Hamilton, J. (1987), Optimal Wage and Income Taxation with Wage Uncertainty, International Economic Review, Vol. 28, No. 2, pp. 373-388.

Hare, P. G. and D. T. Ulph (1979), On Education and Distribution, Journal of Political Economy, Vol. 87, No. 5, pt. 2, pp. 193-212.

Hoff, K. and A. B. Lyon (1995), Non-leaky Buckets: Optimal Redistributive Taxation and Agency Costs, Journal of Public Economics, Vol. 58, No. 3, pp. 365-390.

Hosios, A. J. (1990), On the Efficiency of Matching and Related Models of Search and Unemployment, Review of Economic Studies, Vol. 57, No. 2, pp. 279-298. 
Hubbard, R. G. and K. L. Judd (1986), Liquidity Constraints, Fiscal Policy, And Consumption, Brookings papers on Economic Activity, Vol. 1, No. 1, pp. 1-51.

Jacobs, B. (2005), Optimal Income Taxation with Endogenous Human Capital, Journal of Public Economic Theory, Vol. 7, No. 2, pp. 295-315.

Jacobs, B. (2012), Optimal Redistributive Tax and Education Policies in General Equilibrium, International Tax and Public Finance, DOI, 10.1007/s10797-012-9229-9.

Jacobs, B. and A. L. Bovenberg (2010), Human Capital and Optimal Positive Taxation of Capital Income, International Tax and Public Finance, Vol. 17, No. 5, pp. 451-478.

Jacobs, B. and A. L. Bovenberg (2011), Optimal Taxation of Human Capital and the Earnings Function, Journal of Public Economic Theory, Vol. 13, No. 6. pp. 957971.

Jacobs, B. and S. J. G. van Wijnbergen (2007), Capital-Market Failure, Adverse Selection, and Equity Financing of Higher Education, FinanzArchiv, Vol. 63, No. 1, pp. $1-32$.

Jacobs, B., D. Schindler and H. Yang (2012), Optimal Taxation of Risky Human Capital, Scandinavian Journal of Economics, Vol. 114, No. 3, pp. 908-931.

Jappelli, T. (1990), Who is Credit Constrained in the U.S. Economy? The Quarterly Journal of Economics, Vol. 105, No.1, pp. 219-234.

Jones, L. E., R. E. Manuelli and P. E. Rossi (1993), Optimal Taxation in Models of Endogenous Growth, Journal of Political Economy, Vol. 101, No.3, pp. 485-517.

Judd, K. L. (1999), Optimal Taxation and Spending in General Competitive Growth Models, Journal of Public Economics, Vol. 71, No.1, pp. 1-26.

Kane, T. J. (1995), Rising Public College Tuition and College Entry: How Well do Public Subsidies Promote Access to College. NBER Working Paper No. 5164.

Kane, T. J. (1996), College Cost, Borrowing Constraints and the Timing of College Entry, Eastern Economic Journal, Vol. 22, No. 2, pp. 181-194.

Keane, M. P. and K. I. Wolpin (2001), The Effect of Parental Transfers and Borrowing Constraints on Educational Attainment, International Economic Review, Vol. 42, No. 4, pp. 1051-1103.

Koskela, E. and J. Vilmunen (1996), Tax Progression is Good for Employment in Popular Models of Trade Union Behaviour, Labour Economics, Vol. 3, No. 1, pp. 65-80. 
Layard, R. (1980), Human Satisfactions and Public Policy, The Economic Journal, Vol. 90, No. 360, pp. 737-750.

Layard, R. (2005), Happiness: lessons from a new science, Penguin, London, UK.

Lochner, L. and A. Monge-Naranjo (2011), The Nature of Credit Constraints and Human Capital, American Economic Review, Vol. 101, No. 6, pp. 2487-2529.

Loury, G. C. (1981), Intergenerational Transfers and the Distribution of Earnings, Econometrica, Vol. 49, No. 4, pp. 843-867.

Maldonado, D. (2008), Education Policies and Optimal Taxation, International Tax and Public Finance, Vol. 15, No. 2, pp. 131-143.

Mariger, R. P. (1986), Consumption Behavior and the Effects of Fiscal Policies, Havard University Press, Cambridge.

Mirrlees, J. A. (1971), An Exploration in the Theory of Optimal Income Taxation, Review of Economic Studies, Vol. 38, No. 2, pp. 175-208.

Mookherjee, D. and D. Ray (2003), Persistent Inequality, Review of Economic Studies, Vol. 70, No. 2, pp. 369-393.

Nielsen, S.B., and P.B. Sørensen, 1997, On the Optimality of the Nordic System of Dual Income Taxation, Journal of Public Economics, Vol. 63, No. 3, pp. 311-329.

Pereira, Joana (2009), Essays on Time-Consistent Fiscal Policy, European University Institute, Florence.

Pissarides, C. A. (1998), The Impact of Employment Tax Cuts on Unemployment and Wages; The Role of Unemployment Benefits and Tax Structure, European Economic Review, Vol. 42, No. 1, pp. 155-183.

Plug, E. and W. Vijverberg (2005), Does Family Income Matter for Schooling Outcomes? Using Adoptees as a Natural Experiment, The Economic Journal, Vol. 115, No. 506, pp. 879-906.

Schindler, D. (2011), Tuition Fees and the Dual Income Tax - The Optimality of the Nordic Income Tax System Reconsidered, German Economic Review, Vol. 12, No. 1, pp. 59-84.

Sørensen, P. B. (1999), Optimal Tax Progressivity in Imperfect Labor Markets, Labour Economics, Vol. 6, No. 3, pp. 435-452.

Stern, N. H. (1976), On the Specifications of Models of Optimum Income Taxation, Journal of Public Economics, Vol. 6, No. 1-2, pp. 123-162. 
Stiglitz, J. E. (1994), Whither Socialism? MIT-Press, Cambridge-MA.

Stinebrickner, R. and T. Stinebrickner (2008), The Effect of Credit Constraints on the College Drop-Out Decision: A Direct Approach Using a New Panel Study, American Economic Review, Vol. 98, No. 5, pp. 2163-2184.

Tobin, J. (1980), Asset Accumulation And Economic Activity, The Univesity of Chicago Press, Basil Blackwell, Oxford.

Trostel, P. A. (1993), The Effect of Taxation on Human Capital, Journal of Political Economy, Vol. 101, No. 2, pp. 327-350.

Tuomala, M. (1990), On the Optimal Income Tax and Redistribution. Oxford, Clarendon Press.

Ulph, D. (1977), On the Optimal Distribution of Income and Educational Expenditure, Journal of Public Economics, Vol. 8, No. 3, pp. 341-356.

Varian, H.R. (1980), Redistributive Taxation as Social Insurance, Journal of Public Economics, Vol. 14, No. 1, pp. 49-68.

van der Klaauw, W. (2002), Estimating the Effect of Financial Aid Offers on College Enrollment: A Regression-Discontinuity Approach, International Economic Review, Vol. 43, No. 4, pp. 1249-1287.

van der Ploeg, F. (2006a), Are the Welfare State and Redistribution Really That Bad The Economy? Effects of Reciprocal Altruism, Consumer rivalry and Second-Best, in: F. Farina and E. Savaglio (eds.), Inequality and Economic Integration, Routledge, London.

van der Ploeg, F. (2006b), Do Social Policies Harm Employment? In: Agell J. and P. Srensen (Eds.), Tax Policy and Labour Market Performance, CESifo and MIT Press, Cambridge, Mass.

van Ewijk, C. and P. J. G. Tang (2007), Unions, Progressive Taxes, and Education Subsidies, European Journal of Political Economy, Vol. 23, No. 4, pp. 1119-1139. 